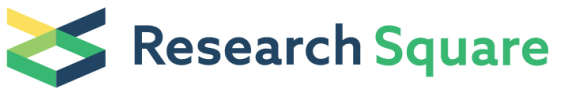 \\ Preprints are preliminary reports that have not undergone peer review. \\ They should not be considered conclusive, used to inform clinical practice, or referenced by the media as validated information.
}

\section{Integrated Analysis of microRNAs and Metabolomics in Rat's Serum Reveals Multi-action Modes of Qingfei Paidu Decoction for COVID-19 Treatment}

\author{
Long-Xue Li \\ Jiangxi University of Traditional Chinese Medicine https://orcid.org/0000-0002-9602-6269 \\ Wei-qi Liu \\ McGill University \\ Yun Liao \\ Nanchang Customs Distrct \\ Zhi-yong Liu \\ Jiangxi University of Traditional Chinese Medicine \\ Yu-ran Chen \\ Jiangxi University of Traditional Chinese Medicine \\ Li-ming Luo \\ Jiangxi University of Traditional Chinese Medicine \\ Hao Chen \\ The Affiliated Hospital of Jiangxi University of Chinses Mrdicine \\ Yu-meng Peng \\ Jiangxi University of Traditional Chinese Medicine \\ Yan-qing Zeng \\ Jiangxi University of Traditional Chinese Medicine \\ Qing-ni Wu \\ Jiangxi University of Traditional Chinese Medicine \\ Tie-Long Xu ( $\nabla$ jxciq_xtl@126.com) \\ Jiangxi University of Chinese Medicine \\ Bin Zheng \\ National Institute of Parasitic Diseases
}

\section{Research Article}

Keywords: COVID-19, Qingfei Paidu decoction, MicroRNA, Metabolomics, Action mode

Posted Date: August 10th, 2021

DOI: https://doi.org/10.21203/rs.3.rs-779200/v1

License: (c) (i) This work is licensed under a Creative Commons Attribution 4.0 International License. Read Full License 


\section{Abstract}

\section{Background}

During the fight against coronavirus disease 2019 (COVID-19) in China, Qingfei Paidu decoction (QFPDD) has been widely applied to treat COVID-19 patients. Retrospective studies showed that QFPDD could improve clinical outcomes of COVID19. Thus, it is necessary and interesting to explore the action mode of QFPDD for further application and development.

\section{Methods}

Sprague-Dawley (SD) rats were randomly divided into two groups, QFPDD $(n=9)$ and control $(n=10)$ groups. They were parallelly treated for 12 days with QFPDD and warm distilled water, respectively. At the endpoint, the microRNA (miRNA or $\mathrm{miR}$ ) profiles in serum were detected to identify differently expressed miRNAs (DEMs). Then, the action mode of QFPDD were explored via review of potential roles of DEMs and functional enrichment analysis of their targets (e.g., GO enrichment and KEGG pathway analysis), especially focusing on the aspects of immunity, inflammation, virus infection and pulmonary fibrosis. Core genes were identified based on KEGG pathway analysis. Metabolomics were detected in serum and significantly changed metabolites (SCMs), especially the metabolic substrates and products of enzyme of core gene were identified as biomarkers to validate the regulation of DEMs to enzyme activity of core gene through metabolomic analysis and linear correlation analysis between SCMs and DEMs.

\section{Results}

23 DEMs were identified in the serum between QFPDD and control groups, with 1636 predicted genes. Reported evidence has showed that both the DEMs and their target genes involve regulation of immunity, inflammation, virus infection and pulmonary fibrosis. Phospholipase $\mathrm{C}$, gamma 1 (Plcg1) was identified as a core gene and predicted to be upregulated attributed to downregulation of novel-89-mature. The levels of three SCMs, PC(P-18:1(11Z)/22:5(4Z,7Z,10Z,13Z,16Z)), PC(22:5(4Z,7Z,10Z,13Z,16Z)/P-18:0) and PC(16:1(9Z)/16:1(9Z)), which were the metabolic substrates of phospholipase C, were significantly reduced in QFPDD group, in addition, PC(P-18:1(11Z)/22:5(4Z,7Z,10Z,13Z,16Z)) and PC(22:5(4Z,7Z,10Z,13Z,16Z)/P-18:0) presented positively linear correlation with the expression level of novel-89-mature. The level of phosphorylcholine, a product of PCs metabolized by phospholipase C, was significantly elevated in QFPDD group.

\section{Conclusion}

QFPDD can induce modification of miRNAs profile, and subsequently multi-regulate the immunity, inflammation, virus infection and pulmonary fibrosis in vivo, playing an important role for the positive outcomes of COVID-19 patients treated by QFPDD in China.

\section{Key Points}

QFPDD can modify individual miRNA profile in organism, which was predicted to:

- directly exert antivirus effect on SARS-CoV-2.

- activate phospholipase $\mathrm{C}$, and the activation was validated by corresponding change of metabolites in the serum.

- attenuate pulmonary fibrosis.

\section{Background}


The COVID-19 is a public health emergency of international concern. Just like many other public health emergencies, neither antiviral drug nor vaccine was available at the early stage, though latest paper reported that 13 vaccines have been put into phase 3 trials worldwide [1]. Chinese medicine is of extensive practical experience for the infectious diseases' prophylaxis and treatment [2], based on which Chinese clinical experts formulated a therapeutic scheme of Chinese medicine at the beginning of the COVID-19 outbreak, using alone or combined with western medicine. In the schedule, QFPDD was highly recommended for all types of COVID-19, namely type mild, general, severe, and critical. The scheme was well implemented in the whole country and almost all the COVID-19 patients have been treated with the scheme. Now, the pandemic has been completely controlled in China. Retrospective studies showed that QFPDD using alone or combined with western medicines could improve clinical outcomes of COVID-19 [3-6]. In particular, early treatment with QFPDD was associated with favorable outcomes, including faster recovery, shorter time to viral shedding, and a shorter duration of hospital stay [6, 7]. The favorable outcomes impelled researcher to study the action mode of QFPDD [8-10].

Chinese herbal formula always holds the characteristics of multi-components, multi-targets, and multi- pathways, playing an omni-bearing regulatory role in the treatment of diseases. QFPDD is a multi-component Chinese herbal formula composed of 21 Chinese medicinal herbs $[11,12]$. In silico studies, e.g., network pharmacology found that these favorable outcomes may be attributed to the anti-viral, anti-inflammatory activities and metabolic programming [8-10, 12-14]. The number of potential targets or signaling pathways regulated by QFPDD can reach up to hundreds, covering dozens of biological functions, involving anti-viral, viral pneumonia, reduction of lung injury, improvement of lung function, cytokine receptor binding, immune regulation, anti-inflammation, biological angiogenesis, and so on [12-14]. Among these biological functions, significant anti-inflammation effects have been observed in a clinical study [9], which might be mediated by MaXingShiGan Decoction, a composition of QFPDD, through regulating thrombin and Toll-like receptor (TLR) signaling pathway [8]. The existing evidence about the multi-action modes of QFPDD is a relatively less convincing due to the lack of in vivo study.

MiRNAs are small non-coding single-stranded RNAs of about $20 \sim 25 \mathrm{nt}$ in length that regulate gene expressions through interactions of their seed region with the complementary sequences in the $3^{\prime}$ - or $5^{\prime}$-untranslated regions ( $3^{\prime}$ or $5^{\prime}$ UTRs) of target mRNAs, inhibiting or promoting their translation and ultimately affect multitude of signaling pathways [15-18]. And miRNAs can be secreted into body fluid or blood, playing a biological effect in the remote cell [17]. In addition, miRNA can directly interact with virus RNA to inhibit virus infection [19]. Therefore, analysis of miRNA profile in rats modulated by QFPDD, integrated with targets and pathway prediction will provide a reasonable and feasible method to explain the multiaction modes of QFPDD. And the modulation of gene expression targeted by DEMs may be observed from metabolomics, which can validate the results of miRNA analysis. Thus, we conducted an integrated analysis of miRNAs and metabolomics, aiming to explore the multi-action modes of QFPDD in a multi-angle manner.

\section{Material And Methods}

\section{Sample preparation}

\section{QFPDD processing}

The components of QFPDD are coordinated with previous study [9]. Briefly, Sheng Shi Gao was decocted firstly in $1500 \mathrm{ml}$ pure water for $5 \mathrm{~min}$, and then the other 20 raw materials were co-decocted in the water until the amount of the solvent was approximately $600 \mathrm{ml}$. The $600 \mathrm{ml}$ decoction was equally portioned and packed into 12 parts, stored at $4^{\circ} \mathrm{C}$ for use.

\section{Rats rearing and QFPDD oral administration}

Six-week-old male Sprague-Dawley (SD) rats originated from the National Laboratory Animal Seed Center and bred at the Experimental Animal Science and Technology Center of Jiangxi University of Traditional Chinese Medicine. The rats were housed at $23 \pm 2^{\circ} \mathrm{C}, 40 \sim 70 \%$ relative humidity, a 12:12 light: dark cycle, and with ad libitum access to normal food and 
water. The rats were orally administrated by warm QFPDD for 12 days at the dosage of $10 \mu \mathrm{L} / \mathrm{g} / \mathrm{d}$, which was equivalent to six times human dosage used in the treatment of COVID, and the control rats were parallelly treated with warm distilled water.

\section{Rats' serum preparation and Constructed groups}

On the first day post the 12-days treatment for the rats, their blood was collected from the abdominal aorta in the absence of anticoagulants. The blood samples were kept static at $4^{\circ} \mathrm{C}$ for $2 \mathrm{~h}$. Then the serum was separated from these blood samples by centrifugation at $4^{\circ} \mathrm{C}$ at $1600 \times \mathrm{g}$ for 10 minutes and stored at $-80^{\circ} \mathrm{C}$ individually until detection and analysis. In such a way, two groups were constructed: 12-day treated serum after oral administration of QFPDD (QFPDD group) and 12-day parallel serum (control group), which included 9 and 11 samples, respectively.

\section{Sequencing of miRNAs profile}

\section{RNA isolation}

Total RNA was extracted from the blood serum using the Total RNA Extractor \Trizol $\llbracket$ kit (B511311, Sangon, China) according to the manufacturer's protocol, and treated with RNase-free DNase $\nabla$ to remove genomic DNA contamination. RNA integrity was evaluated with a $1.0 \%$ agarose gel. Thereafter, the quality and quantity of RNA were assessed using a Nano Photometer ® spectrophotometer (IMPLEN, CA, USA) and an Agilent 2100 Bioanalyzer (Agilent Technologies, CA, USA). The high-quality RNA samples were subsequently submitted to the Sangon Biotech (Shanghai) Co., Ltd. for library preparation and sequencing. Concentration of total RNAs extracted from the serum of QFPDD and control group ranged from $0.534 \sim 0.720 \mu \mathrm{g} / \mu \mathrm{L}$ in $30 \mu \mathrm{L}$ total volume, and integrity showed that the samples meet the requirements for sample preparation.

\section{Small RNA library preparation and sequencing}

A total of $2 \mu \mathrm{g}$ total RNA per sample was used as input material for small RNA library preparations. Sequencing libraries were generated using NEBNext® Multiplex Small RNA Library Prep Set for Illumina ${ }^{\circledR}$ (NEB, USA.) following manufacturer's recommendations. Total RNA was used as the starting sample, the small RNA ends are directly connected with the adapter, followed by reverse transcription synthesis into cDNA. DNA fragments of 140-150 bp were separated by PAGE gel electrophoresis, and the cDNA library was recovered. Finally, library quality was assessed on the Agilent Bioanalyzer 2100 system, and libraries were sequenced on an Illumina HiSeq X-ten platform.

\section{Raw Reads Quality Control}

The first step in our data analysis is removing adapters with software cutadapter (1.14), then low quality ( $₫ 20)$ bases from both 3 ' end and 5 ' end were trimmed with Trimmomatic (v0.36). Reads length ranging from 17bp and 35bp were reserved. We used FastQC and in house scripts to generate QC report, which could help us to spot problems originating from either library preparation or sequencing process. We reviewed sequence quality metrics including per base quality scores (Q30), GC content, $\mathrm{N}$ content, Kmer content and duplicate levels, base bias at each position, copy number, length distribution, bases proportion, etc. Fastq to fasta conversion and removal of duplication were conducted for further data analysis.

\section{Reads Filter}

As other small RNA and fragments from mRNA degradation may get introduced in library preparation, reads mapped to other small RNA (rRNA, sRNA, snRNA, snoRNA) and mRNA sequence using blastn (2.6.0) and bowtie (1.1.1) respectively, were removed. The remaining reads were mapped to species genome sequence, and unmapped reads were filtered.

\section{MiRNA analysis}


The known mature miRNA and precursor miRNA of the species were archived from mirBase (v21). We used mirDeep2 (v2.0.0.8) to discover novel miRNAs, predicate hairpin structure of precursor-miRNA and quantify miRNA. The alignment result (mrd format) was used to detect miRNA modification, which originated from SNP and RNA-editing. As miRNA are evolutionary conserved, we summarized numerical counts and reads counts of known miRNA family.

\section{Differentially Expressed MicroRNAs (DEMs) Detection}

We used an R package edgeR (v3.18.1) to compare expression levels between sample pairs. We used fold change $>2$ and $p$ value $<0.05$ as thresholds to define significantly differentially expressed miRNAs. To give an overview of the difference status of gene expression, we used volcano plots, MA plot and scatter plot to present the genes with differential expression between the paired samples.

\section{Functional enrichment analysis}

First, all genes were mapped to each term of the GO database (http://www. geneontology.org/) and the gene numbers of each GO term were calculated to get a gene list. Then the hypergeometric test was used to find significantly enriched GO terms in differentially expressed genes (DEGs) compared with the genome background. After Bonferroni correction, GO terms with corrected $P \leq 0.05$ were defined as significantly enriched GO terms. Similarly, by applying a cut-off criterion of Qvalue $<0.05$, pathway enrichment analysis was performed by comparing the Kyoto Encyclopedia of Genes and Genomes (KEGG) pathway annotations with the whole gene background. To better understand the function of the significantly differentially expressed miRNA, we used R package clusterProfiler (3.4.4) to do functional enrichment of target genes. Bar plot and scatter plot were created to demonstrate top significantly enriched term (top 10 gene ontology and top 20 pathways). Top term gene-term and term-term interactive network plot were implemented in R package igraph (1.1.2).

\section{Detection of metabolomics}

\section{Metabolites Extraction}

$100 \mu \mathrm{L}$ of serum was transferred to an EP tube. After the addition of $400 \mu \mathrm{L}$ of extract solution (acetonitrile: methanol = $1: 1$, containing isotopically labelled internal standard mixture), the samples were vortexed for $30 \mathrm{~s}$, sonicated for $10 \mathrm{~min}$ in ice-water bath, and incubated for $1 \mathrm{~h}$ at $-40{ }^{\circ} \mathrm{C}$ to precipitate proteins. Then the sample was centrifuged at $12000 \mathrm{rpm}$ $(\mathrm{RCF}=13800(\times g), \mathrm{R}=8.6 \mathrm{~cm})$ for $15 \mathrm{~min}$ at $4{ }^{\circ} \mathrm{C}$. The resulting supernatant was transferred to a fresh glass vial for analysis. The quality control (QC) sample was prepared by mixing an equal aliquot of the supernatants from all the samples.

\section{liquid chromatography-mass spectrometry (LC-MS/MS) Analysis}

LC-MS/MS analyses were performed using an UHPLC system (Vanquish, Thermo Fisher Scientific) with a UPLC BEH Amide column $(2.1 \mathrm{~mm} \times 100 \mathrm{~mm}, 1.7 \mu \mathrm{m})$ coupled to Q Exactive HFX mass spectrometer (Orbitrap MS, Thermo). The mobile phase consisted of $25 \mathrm{mmol} / \mathrm{L}$ ammonium acetate and 25 ammonia hydroxide in water $\ \mathrm{pH}=9.75 \rrbracket(A)$ and acetonitrile (B). The auto-sampler temperature was $4{ }^{\circ} \mathrm{C}$, and the injection volume was $3 \mu \mathrm{L}$.

The QE HFX mass spectrometer was used for its ability to acquire MS/MS spectra on information-dependent acquisition (IDA) mode in the control of the acquisition software (Xcalibur, Thermo). In this mode, the acquisition software continuously evaluates the full scan MS spectrum. The ESI source conditions were set as following: sheath gas flow rate as 30 Arb, Aux gas flow rate as 25 Arb, capillary temperature $350^{\circ} \mathrm{C}$, full MS resolution as $60000, \mathrm{MS} / \mathrm{MS}$ resolution as 7500 , collision energy as 10/30/60 in NCE mode, spray Voltage as 3.6 kV (positive) or -3.2 kV (negative), respectively.

\section{Data preprocessing and annotation}

The raw data were converted to the mzXML format using ProteoWizard and processed with an in-house program, which was developed using R and based on XCMS, for peak detection, extraction, alignment, and integration. SIMCA software 
(v16.0.2) was used for multivariate statistical analysis. Orthogonal partial least squares discriminant analysis (OPLS-DA) and student's t-test were employed to identify significantly changed metabolites (SCMs).

\section{Results}

\section{Analysis of miRNAs profiles in the serum of rats treated with QFPDD High-throughput sequencing and annotation of small RNAs in SD rats}

To evaluate the impact of QFPDD on miRNA expression in SD rats, we performed Illumina sequencing on small RNA libraries obtained from QFPDD treated rats and compared the miRNA profiles with untreated rats. Approximately $9.69 \sim$ 18.16 million reads were obtained from the 20 samples included in the two groups (Additional file 1). And after removal of adaptors, contaminants, and low-quality reads, approximately $8.20 \sim 15.52$ million clean reads ranged from $17 \sim 35 \mathrm{nt}$ were obtained (Additional file 2). Intron, exon, tRNA, rRNA, miRNA, snRNA and snoRNA reads were annotated, respectively, as shown in Additional file 3. The length distribution of clean reads peaked at about $22 \mathrm{nt}$ for all the samples.

\section{The identification of known and novel miRNAs}

The known mature miRNA and precursor miRNA of the species were archived from mirBase (v21). We used mirDeep2 (v2.0.0.8) to discover novel miRNAs, predicate hairpin structure of precursor-miRNA, and quantify miRNA. To identify known miRNAs, we aligned the small RNAs to the known mature miRNAs and their precursors in miRBase 21 to obtain the miRNA counts as well as the base bias at the first position. Approximately 133,462 22,046 unique sequences in the two groups' library were annotated as miRNA candidates (Additional file 3). A total of 585 known miRNA genes were identified (Additional file 4). The miRNAs ranged in size from 17 to $25 \mathrm{nt}$, with $71.62 \%$ from 21 to 22 , and the base bias at the first position of the identified miRNAs showed a strong preference for ' $U$ ' at the 5 '-end, which is coordinated with previous studies [20].

After removing the snRNAs, snoRNAs, rRNAs, tRNAs, and known miRNAs, we aligned the remaining unannotated reads against the Rattus norvegicus genome to predict novel miRNAs. A total of 1622 potential novel miRNA reads were mapped in control and QFPDD treated samples. The miRNAs are shown in Additional file 5, along with their Dicer cleavage site, minimum free energy, frequency of reads and typical secondary structures of the characteristic stem-loop hairpins for the predicted precursors.

\section{Changes in miRNA expression profiles and prediction of targets}

We normalized the expression of each miRNA (Additional file 6) as reads count per million (CPM) and calculated the QFPDD treated and untreated rat's serum miRNA expression ratio (Additional file 6). We further analyzed the expression data by calculating the fold changes and $P$-values based on the expression ratios and plotted these data as a scatter plot. Changes after oral administration of QFPDD were apparent (Fig. 1a). The upregulated miRNAs were more numerous than the downregulated miRNAs.

Using a |fold-changel $\geq 2$ and $P$ value $\leq 0.05$ to screen the miRNAs, a total of 23 DEMs were identified (Additional file 7 and 8). Of these miRNAs, 20 were statistically upregulated (miR-10b-3p, miR-1-3p, miR-100-5p, miR-199a-3p, miR-1b, miR205, miR-206-3p, miR-214-3p, miR-218a-5p, miR-34b-5p, miR-3594-3p, miR-383-3p, miR-466b-5p, novel-1149-mature, novel227-mature, novel-280-mature, novel-595-mature, novel-667-mature, novel-754-mature and novel-98-star), and 3 were significantly downregulated (novel-1138-mature, novel-614-mature, and novel-89-mature) in QFPDD treated group. Ten of the significantly differentially expressed miRNAs are putative novel miRNA (Fig. 1b).

\section{Multi-action modes of QFPDD directly induced by the known DEMs}

Of the 13 known DEMs, 11 had been reported to be involved by the regulation of immunity, inflammation, multi-organ fibrosis, and virus infection (Table 1). In particular, miR-1-3p, miR-10b-3p and miR-199a-3p may possess antivirus effect on 
SARS-CoV-2 [21, 22], and miR-199a-3p, miR-206-3p and miR-214-3p can attenuate the pulmonary fibrosis [23-25]. However, it is contradictory that miR-34b-5p is significantly upregulated by QFPDD, which may promote inflammation and pulmonary fibrosis $[26,27]$.

Table 1

The potential role of DEMs during SARS-Cov-2 infection induced by reported evidence.

\section{miRNA Potential role during SARS-CoV-2 infection induced by reported evidence name}

miR-1- Involving regulation of immunity [28], inflammation [28-30], multi-organ fibrosis [31-33], and virus infection, $3 p \quad$ e.g., SARS-CoV-2, EBOV, IAV [21, 34-36]

miR- Involving regulation of inflammation [37]

$1 \mathrm{~b}$

miR- Involving regulation of immunity [38-40], HBV-associated liver fibrosis [41] and virus infection, e.g., SPPV, 10b-3p SARS-CoV-2, EBV, KSHV, HIV and many other retroviruses [22, 42-44]

miR- Involving regulation of immunity [45, 46], pulmonary inflammation [26, 47-49] and fibrosis [27] and virus $34 b-5 p$ infection, e.g., ALV-J, RSV [50, 51]

miR- Involving regulation of immunity [52, 53], inflammation [54-56], virus infection, e.g., H5N1, HBV [57, 58] $100-5 p$

miR- Involving regulation of immunity [59-61], inflammation [23, 62-65], multi-organ fibrosis [23, 66-70], virus 199a- infection [71], e.g., HBV, PRRSV, SARS-CoV-2, HCV, HBV [21, 67, 72-74]

$3 p$

miR- Involving regulation of inflammation [75-79], multi-organ (especially pulmonary) fibrosis [80-82], virus 205 infection, e.g., HCV, HIV, HBV, EBV, HPV [83-87]

miR- Involving regulation of immune [88], multi-organ (especially pulmonary) fibrosis [24], virus infection, e.g., 206-3p BoDV [89]

miR- Involving regulation of immune [90], inflammation [91-96],multi-organ (especially pulmonary) fibrosis [25,

214-3p 93], virus infection, e.g., HCMV [97]

miR- Involving regulation of inflammation [98]

383-3p

miR- Involving regulation of inflammation [99]

$466 b-$

$5 p$

Note: SARS-CoV-2, severe acute respiratory syndrome coronavirus-2; EBOV, ebola virus; IAV, influenza A virus; SPPV, sheep pox virus; KSHV, kaposi sarcoma-associated herpesvirus; HIV, human immunodeficiency virus; ALV-J, Avian leukosis virus subgroup J; RSV, respiratory syncytial virus; H5N1, Influenza A virus H5N1; HBV, hepatitis B virus; PRRSV, porcine reproductive and respiratory syndrome virus; HCV, hepatitis C virus; EBV, epstein-barr virus; HPV, human papillomavirus; BoDV, Borna disease virus; HCMV, Human cytomegalovirus.

\section{Multi-action modes of QFPDD indirectly induced by the predicted targets of DEMs Action mode induced by the top 100 predicted targets ranked by score}

To investigate the regulated miRNAs functions, we predicted the potential targets of the 23 DEMs. A total of 2088 targets, covering 1636 regulated genes were predicted (Additional file 9). The top 100 regulated genes ranked by score were specifically selected out for further analysis, of which $42 \%$ (42/100) were reported to be involved in regulation of at least one kind of virus infection (Additional file 10). Especially, seven target genes might facilitate SARS-CoV-2 infection [100103] or be related to symptoms of COVID-19 [104-112], including fatty acid synthase (Fasn) [100], VPS39 HOPS complex subunit (Vps39) [101, 102], sodium channel epithelial 1 alpha subunit (Scnn1 $a$ or ENaC- $a$ ) [109, 113], solute carrier family 6 
member 19 (Slc6a19 or $\mathrm{B}^{0} \mathrm{AT} 1$ ) [104-108], ADP-ribosylarginine hydrolase (Adprh) [103], C-C motif chemokine receptor 9 (Ccr9) $[110,111]$, WNK lysine deficient protein kinase 1 (Wnk1) [112]. Fasn, VPS39 and Adprh may be required for SARSCoV-2 replication[100, 103] or infection $[101,102]$. ENaC- $a, B^{0}$ AT1 and CCR9 were strategically mimicked or regulated by SARS-CoV-2 infection, leading to respiratory symptoms or respiratory failure [109-111], intestinal inflammation and nutritional status [104-108] in COVID-19 patients. Moreover, Wnk1 could fight against cytokine storm caused by sepsis in COVID-19 patients [112].

\section{Overview of functions induced by GO enrichment analysis}

GO enrichment covers three domains: biological processes partaken by target genes, cellular components containing target genes, and molecular functions possessed by target genes. GO categorization showed that the first five biological process of target genes were the cellular process, single-organism process, metabolic process, response to stimulus, multicellular organismal process and cellular component organization or biogenesis. Five molecular function of target genes, namely binding, catalytic activity, transporter activity, molecular function regulator, and signal transducer activity were most enriched. The genes located at cell, organelle, membrane, macromolecular complex, or membrane-enclosed lumen were most significant among the cellular component GO terms (Fig. 2a). More potential roles covered by target genes in every domain were presented in Fig. 2a and Additional file 11. Then, the gene numbers of each GO term, regulated by DEMs were calculated (Additional file 12), and based on a cut-off criterion of $P$ value $<0.05$, top ten $\mathrm{GO}$ terms with most gene numbers in every domain were showed in Fig. $2 b$.

\section{Multi-action modes induced by KEGG pathway analysis}

KEGG pathway is a collection of manually drawn pathway maps representing our knowledge on the aspects of molecular interaction, reaction and relation networks for metabolism, genetic information processing, environmental information processing, cellular processes, organismal systems, human diseases, and drug development. KEGG categorization showed that the first ten pathways involved signal transduction, infectious diseases, endocrine system, cancers, immune system, signaling molecules and interaction, cellular community, nervous system, transport and catabolism, and development (Fig. 3a, Additional file 13). The gene numbers of each KEGG ID were calculated (Additional file 14, Additional file 15a), based on a cut-off criterion of Q-value $<0.05$, top twenty KEGG enrichments were selected for individual analysis (Fig. 3b). The KEGG pathway enrichment analysis revealed some important pathways that were significantly enriched in response to QFPDD treatment, including the NF-kappa B signaling pathway, Cytokine-cytokine receptor interaction, MAPK signaling pathway, signaling pathways regulating pluripotency of stem cells, Jak-STAT signaling pathway, Toll-like receptor signaling pathway, and RAS signaling pathway (Table 2). In addition, a putative network between significantly expressed miRNAs and their target genes was established for the top KEGG enrichments (Additional file 15a, b). According to the network, the top five core genes ranked by edges were selected for function analysis (Table 3). According to the reported evidence showed in Tables 2-3, these important KEGG pathways (Table 2) and the five core genes (Table 3) may play a positive role in SARS-CoV-2 infection through regulating immunity, inflammatory cytokines, virus infection and pulmonary fibrosis. 
Table 2

Important KEGG pathways enriched in response to QFPDD treatment and their potential roles in SARS-CoV-2 infection induced by reported evidence.

\begin{tabular}{|c|c|}
\hline KEGG pathway & Potential role during SARS-CoV-2 infection induced by reported evidence \\
\hline $\begin{array}{l}\text { NF-kappa B signaling } \\
\text { pathway }\end{array}$ & $\begin{array}{l}\text { Involving regulation of immunity }[114,115] \text {, inflammatory cytokines }[114,116-120] \text {, } \\
\text { pulmonary fibrosis }[121] \text {, and virus infection, e.g., SARS-CoV-2, H1N1 }[115-117,119- \\
124]\end{array}$ \\
\hline $\begin{array}{l}\text { Cytokine-cytokine receptor } \\
\text { interaction }\end{array}$ & $\begin{array}{l}\text { Involving regulation of immunity and inflammatory cytokines }[125,126] \text {, virus infection, } \\
\text { e.g., SARS-CoV-2, DHAV, PDCoV, RSV }[125,127-131]\end{array}$ \\
\hline MAPK signaling pathway & $\begin{array}{l}\text { Involving regulation of immunity and inflammatory cytokines [132-137], virus infection, } \\
\text { e.g., PDCoV, HIV, H1N1, SARS-CoV-2, FMDV, IAV [133-144] }\end{array}$ \\
\hline $\begin{array}{l}\text { signaling pathways } \\
\text { regulating pluripotency of } \\
\text { stem cells }\end{array}$ & Involving regulation of virus infection, e.g., SARS-CoV-2, IAV [145-153] \\
\hline $\begin{array}{l}\text { Jak-STAT signaling } \\
\text { pathway }\end{array}$ & $\begin{array}{l}\text { Involving regulation of immunity [154], inflammatory cytokines [154-160], virus } \\
\text { infection [161], e.g., SARS-CoV-2, HBV, IV, Flavivirus [154-157, 159, 160, 162-167] }\end{array}$ \\
\hline $\begin{array}{l}\text { Toll-like receptor signaling } \\
\text { pathway }\end{array}$ & $\begin{array}{l}\text { Involving regulation of inflammatory cytokines }[157,168] \text {, virus infection [71], e.g., HCV, } \\
\text { EBV, SARS-CoV-2, IV }[157,168-171]\end{array}$ \\
\hline RAS signaling pathway & $\begin{array}{l}\text { Involving regulation of virus infection, e.g., herpesviruses, HCMV, HTLV, HSV, HIV, } \\
\text { reovirus, SARS-CoV-2, IV [172-180] }\end{array}$ \\
\hline \multicolumn{2}{|c|}{$\begin{array}{l}\text { Note: SARS-CoV-2, severe acute respiratory syndrome coronavirus-2; DHAV, duck hepatitis A virus; PDCoV, porcine } \\
\text { deltacoronavirus; FMDV, Foot-and-Mouth Disease Virus; RSV, respiratory syncytial virus; HIV, human immunodeficiency } \\
\text { virus; IAV, influenza A virus; HBV, hepatitis B virus; IV, influenza virus; HCV, hepatitis C virus; EBV, epstein-barr virus; } \\
\text { HCMV, Human Cytomegalovirus; HTLV, human T-cell leukemia virus; HSV, herpes simplex virus; H1N1, Influenza A virus } \\
\text { H1N1 2009. }\end{array}$} \\
\hline
\end{tabular}


Table 3

Core genes obtained from KEGG enrichment network analysis.

\begin{tabular}{|c|c|c|c|}
\hline Gene name & $\begin{array}{l}\text { Regulated } \\
\text { miRNA }\end{array}$ & Edges & Potential role during SARS-CoV-2 infection induced by reported evidence \\
\hline $\begin{array}{l}\text { SOS Ras/Rac } \\
\text { guanine nucleotide } \\
\text { exchange factor } 1 \\
\text { (Sos1) }\end{array}$ & $\begin{array}{l}\text { novel- } \\
\text { 754- } \\
\text { mature }\end{array}$ & 7 & $\begin{array}{l}\text { Predicted to be targeted by SARS-CoV-2 encoded miRNA [164], involving } \\
\text { regulation of inflammatory cytokines [181], virus infection, e.g., SARS- } \\
\text { CoV-2, enterovirus } 71, \mathrm{HCV}[164,182,183] \text {, development of fibrosis [184, } \\
185]\end{array}$ \\
\hline $\begin{array}{l}\text { epidermal growth } \\
\text { factor (Egf) }\end{array}$ & $\begin{array}{l}\text { novel- } \\
614- \\
\text { mature }\end{array}$ & 7 & $\begin{array}{l}\text { Involving regulation of ACE2 [186], immunity [187-189], inflammatory } \\
\text { cytokines [190-192], virus infection [193-203], especially SARS-CoV-2 } \\
{[196,198-201,204-206] \text {, multi-organ (especially pulmonary) fibrosis }} \\
{[207-210]}\end{array}$ \\
\hline $\begin{array}{l}\text { phospholipase C, } \\
\text { gamma } 1 \text { (Plcg1) }\end{array}$ & $\begin{array}{l}\text { novel-89- } \\
\text { mature }\end{array}$ & 6 & $\begin{array}{l}\text { Involving regulation of immunity [211, 212], virus infection, e.g., HTLV, } \\
\text { DHBV [213-215], liver fibrosis [216] }\end{array}$ \\
\hline $\begin{array}{l}\text { SHC adaptor } \\
\text { protein } 3 \text { (Shc3) }\end{array}$ & $\begin{array}{l}\text { novel- } \\
614- \\
\text { mature }\end{array}$ & 5 & Involving regulation of immunity $[217,218]$ \\
\hline $\begin{array}{l}\text { A-Raf proto- } \\
\text { oncogene, } \\
\text { serine/threonine } \\
\text { kinase (Araf) }\end{array}$ & $\begin{array}{l}\text { miR- } \\
3594- \\
3 p / \text { novel- } \\
280- \\
\text { mature }\end{array}$ & 5 & $\begin{array}{l}\text { Involving regulation of immunity [219, 220], inflammatory cytokines [221, } \\
\text { 222], virus infection, e.g., H1N1, HBV [223-225] }\end{array}$ \\
\hline
\end{tabular}

\section{Analysis of metabolomics and identification of SCMs in the serum of rats treated with QFPDD}

In this study, 5339 and 4434 peaks (metabolites) were detected in positive ion mode (POS)(Additional file 16a) and negative ion mode (NEG) (Additional file 16b) respectively, and the raw data was processed according to the reported reference [226]. Briefly, the original data was de-noised based on relative standard deviation, and the missing values were filled up by half of the minimum value. Then, total ion current (TIC) was employed to normalize the data. After these processing, The final dataset contained 4181 and 3446 peaks (metabolites) were left for subsequent analysis, in positive

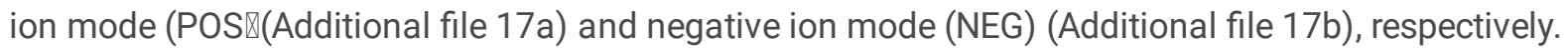

The final dataset containing the information of peak number, sample name and normalized peak area was imported to SIMCA16.0.2 software package (Sartorius Stedim Data Analytics AB, Umea, Sweden) for multivariate analysis. Data was scaled and logarithmic transformed to minimize the impact of both noise and high variance of the variables. Then, supervised orthogonal projections to latent structures-discriminate analysis (OPLS-DA) was applied to identify SCMs between QFPDD and control groups [227] (Additional files 18a and 18b). In the OPLA-DA analysis, the value of variable importance in the projection (VIP) of the first principal component was obtained. It summarizes the contribution of each variable to the model. The metabolites with VIP $>1, p<0.05$ (calculated by student $t$-test) were considered as SCMs. Finally, the 10 SCMs were identified, including phosphorylcholine, 13S-hydroxyoctadecadienoic acid, PC(16:1 (9Z)/16:1(9Z)), PC(P18:1(11Z)/22:5(4Z,7Z,10Z,13Z,16Z)), PC(22:5(4Z,7Z,10Z,13Z,16Z)/P-18:0), beta-thujaplicin, octadecylamine, carnosol, glycyrrhetinic acid, 3-(3-Hydroxyphenyl) propanoic acid, of which, six SCMs belongs to lipids or lipid-like molecules (Table 4). 
Table 4

The significantly changed metabolites (SCMs) in the serum of rats treated with QFPDD.

\begin{tabular}{|c|c|c|c|c|c|c|c|}
\hline Compound name & SuperClass & VIP & $\begin{array}{l}\text { Scan } \\
\text { mode }\end{array}$ & $\begin{array}{l}\text { Trend } \\
(\mathrm{T} / \mathrm{C})\end{array}$ & $\begin{array}{l}P \\
\text { value }\end{array}$ & $\begin{array}{l}\text { Fold } \\
\text { change }\end{array}$ & $\begin{array}{l}\text { Log2 } \\
\text { foldchange }\end{array}$ \\
\hline Phosphorylcholine & $\begin{array}{l}\text { Organonitrogen } \\
\text { compounds }\end{array}$ & 2.14 & $\mathrm{ESI}^{+}$ & $\uparrow$ & 0.04 & 1.30 & 0.38 \\
\hline 13S-hydroxyoctadecadienoic acid & $\begin{array}{l}\text { Lipids or lipid-like } \\
\text { molecules }\end{array}$ & 2.00 & $\mathrm{ESI}^{+}$ & $\uparrow$ & 0.04 & 1.35 & 0.43 \\
\hline PC(16:1(9Z)/16:1(9Z)) & $\begin{array}{l}\text { Lipids or lipid-like } \\
\text { molecules }\end{array}$ & 1.99 & $\mathrm{ESI}^{+}$ & $\downarrow$ & 0.03 & 0.81 & -0.30 \\
\hline $\begin{array}{l}\text { PC(P- } \\
18: 1(11 Z) / 22: 5(4 Z, 7 Z, 10 Z, 13 Z, 16 Z))\end{array}$ & $\begin{array}{l}\text { Lipids or lipid-like } \\
\text { molecules }\end{array}$ & 2.35 & $\mathrm{ESI}^{+}$ & $\downarrow$ & 0.04 & 0.81 & -0.30 \\
\hline $\mathrm{PC}(22: 5(4 Z, 7 Z, 10 Z, 13 Z, 16 Z) / P-18: 0)$ & $\begin{array}{l}\text { Lipids or lipid-like } \\
\text { molecules }\end{array}$ & 2.24 & $\mathrm{ESI}^{+}$ & $\downarrow$ & 0.02 & 0.64 & -0.64 \\
\hline beta-Thujaplicin & $\begin{array}{l}\text { Hydrocarbon } \\
\text { derivatives }\end{array}$ & 2.16 & $\mathrm{ESI}^{+}$ & $\downarrow$ & 0.02 & 0.83 & -0.27 \\
\hline Octadecylamine & $\begin{array}{l}\text { Organonitrogen } \\
\text { compounds }\end{array}$ & 1.95 & $\mathrm{ESI}^{+}$ & $\uparrow$ & 0.04 & 1.23 & 0.30 \\
\hline Carnosol & $\begin{array}{l}\text { Lipids or lipid-like } \\
\text { molecules }\end{array}$ & 1.99 & $\mathrm{ESI}^{+}$ & $\uparrow$ & 0.04 & 1.24 & 0.30 \\
\hline Glycyrrhetinic acid & $\begin{array}{l}\text { Lipids or lipid-like } \\
\text { molecules }\end{array}$ & 2.96 & $\mathrm{ESI}^{-}$ & $\uparrow$ & 0.004 & 3.05 & 1.61 \\
\hline 3-(3-Hydroxyphenyl) propanoic acid & $\begin{array}{l}\text { Phenylpropanoids } \\
\text { or polyketides }\end{array}$ & 2.65 & $\mathrm{ESI}^{-}$ & $\uparrow$ & 0.04 & 1.41 & 0.49 \\
\hline
\end{tabular}

\section{Statistical and theoretical linear correlation between DEMs and SCMs}

To verify the regulation of DEMs, we performed an analysis of correlation between the 23 DEMs and 10 SCMs. Especially, the metabolites related to the core enzyme gene, phospholipase $C$, targeted by novel-89-mature, were paid more attention.

It was interesting to find that three SCMs, PC (16:1(9Z)/16:1(9Z)), PC (P18:1(11Z)/22:5(4Z,7Z,10Z,13Z,16Z)), PC (22:5(4Z,7Z,10Z,13Z,16Z)/P-18:0) belonged to a kind of phosphatidylcholines (PCs) which could be metabolized into phosphorylcholine by phospholipase $\mathrm{C}$ [228]. It meant that phosphorylcholine (another SCM) was the product of PCs metabolized by phospholipase C. More importantly, phospholipase C, gamma 1 (Plcg1) was predicted to be targeted by novel-89-mature.

To further confirm their correlation, we conducted an analysis of linear correlation between the 10 SCMs and novel-89mature, along with the other 22 DEMs. Interestingly, novel-89-mature was significantly positively correlated with PC (P18:1(11Z)/22:5(4Z,7Z,10Z,13Z,16Z)), PC (22:5(4Z,7Z,10Z,13Z,16Z)/P-18:0), with the Pearson product moment coefficient $(r)$ being $0.663(P=0.001)$ and $0.536(p=0.015)$ respectively. Meanwhile, no significant correlation was found between novel-89-mature and the other three SCMs (Fig. 4).

Confusingly, miR-10b-3p and novel-89-mature were found to be significantly positively correlated with 13Shydroxyoctadecadienoic acid and beta-thujaplicin, with $r=0.761(P<0.0001)$ and $r=0.575(P<0.01)$ respectively. Both miR-34b-5p and miR-466b-5p were statistically positively correlated with octadecylamine, with $r=0.579(P<0.01)$ and $r=$ 
$0.467(P<0.05)$, respectively. Moreover, novel-89-mature was negatively correlation with 3-(3-Hydroxyphenyl) propanoic acid, with $r=-0.56(P<0.05)$. However, we only found statistical correlation between these miRNAs and metabolites, waiting for further theoretical interpretations. Except the linear correlation mentioned above, no other linear correlation was found between the 23 DEMs and 10 SCMs.

\section{Discussion}

In this study, 20 SD rats were randomly divided into two groups, namely QFPDD group $(n=9)$ and control group $(n=11)$. They were parallelly treated for 12 days with QFPDD and warm distilled water, respectively. The preparation and treatment of QFPDD in our study were in accordance with the clinical administration of QFPDD during COVID-19 patients' treatment [7]. At the endpoint, there is no difference between the two groups in the terms of weight, whole blood cell count, routine biochemistry indicators of the functions of liver and kidney (the data not showed here), suggesting the safety of QFPDD, to a certain extent. Notably, three rats in the QFPDD group (3/9, approximately 33.33\%) were symptomized with mild diarrhea during the 12 days, of which one recovered itself and the other two got the symptom at the day of the endpoint. However, this phenomenon just obeyed the treatment principle of QFPDD from the view of Chinese medicine, while mild diarrhea is deemed to be detoxifying COVID-19 patients only if the times of diarrhea were no more than 3 per day and feces do not look like watery stool.

This study was conducted according to a study flow chart mainly divided into three steps: 1) obtaining DEMs from QFPDD treated serum of rats, 2) analyzing the multi-action modes of QFPDD though analysis of potential roles of DEMs or their regulated genes, 3) validating the regulation of DEMs by SCMs, especially the products of key enzyme, Plcg1, targeted by novel-89-mature. A total of 23 DEMs in response to QFPDD were identified in the first step, with 13 known miRNAs and 10 novel miRNAs (Fig. 1). Then, the potential role of the 13 known miRNAs were summarized based on existing evidence (Table 1). Apart from miR-3594-3p and miR-218a-5p, the left 11 miRNAs have been reported to involve regulation of immunity, inflammation, multi-organ (including pulmonary) fibrosis, or virus infection (Table 1). Especially, miR-1-3p, miR10b-3p and miR-199a-3p may possess antivirus effect on SARS-CoV-2 [21, 22]. These potential roles of DEMs were further supported by the analysis of their predicted target genes as follows.

On one hand, among the top 100 predicted target genes of DEMs, 42\% (42/100) have been reported to be involved in regulation of at least 33 kinds of virus infection (Additional file 10). Especially, Fasn, Adprh, VPS39, Scnn1a, Slc6a19, Ccr9 may facilitate SARS-CoV-2 infection [100-103] or be related to symptoms, like intestinal inflammation and nutritional status [104-108], respiratory conditions [109] or respiratory failure [110,111] in COVID-19 patients, and Wnk1 could fight against cytokine storm caused by sepsis in COVID-19 patient [112]. Their down- or up-regulations by corresponding miRNAs [19] can play a positive role in the treatment of COVID-19 with QFPDD.

On the other hand, GO enrichment and KEEG enrichment analysis for the target genes allowed us to take an overview of functions of DEMs (Figs. 2-3). Important KEGG pathways and core genes obtained from KEGG enrichment network analysis were selected for further analysis (Tables 2 and 3). Based on literature review, both the important KEGG pathways and core genes regulated by DEMs involved the regulation of immunity, inflammation, multi-organ (including pulmonary) fibrosis, or virus infection (Tables 2 and 3). Impressively, each important KEGG pathway has already been reported to involve SARS-CoV-2 infection (Table 2). In addition, the core gene, SOS Ras/Rac guanine nucleotide exchange factor 1 (Sos1), was predicted to be targeted by SARS-CoV-2 encoded miRNA [164], and epidermal growth factor (Egf) involved regulation of angiotensin-converting enzyme 2 (ACE2), a receptor for SARS-CoV-2 infection [229] (Table 3).

Interestingly, one of the core genes, phospholipase C, gamma 1 (Plcg1) was a kind of lipid metabolic enzyme [228], which provided a possibility to validate the regulation of DEMs through the metabolites of enzyme of core genes (Table 3). Analysis of metabolomics in the serum of rats treated with QFPDD identified 5 SCMs (Table 4). Theoretically, the three SCMs, PC (16:1(9Z)/16:1(9Z)), PC (P18:1(11Z)/22:5(4Z,7Z,10Z,13Z,16Z)), PC (22:5(4Z,7Z,10Z,13Z,16Z)/P-18:0) were the

Page $12 / 29$ 
metabolic substrates of phospholipase $C$, and the product of the enzyme was another one SCM, phosphorylcholine [228]. Phospholipase C, gamma 1 (Plcg1) was targeted by novel-89-mature which was downregulated by QFPDD in SD rats. Generally, the downregulation of novel-89-mature can decrease degradation of mRNA of phospholipase C, enhancing the activity of phospholipase $C$, which means that the less of novel-89-mature expressed, the higher the activity of phospholipase C [19]. Supportively, the enzymatic reaction from PCs to phosphorylcholine was strengthened by the enhancement of activity of phospholipase C, leading to the reduction of PCs and elevation of phosphorylcholine in the serum of rats. Thus, our findings of the reduced levels of the three kinds of PCs and the elevated level of phosphorylcholine (Table 4), especially the levels of PC (P18:1(11Z)/22:5(4Z,7Z,10Z,13Z,16Z)) and PC (22:5(4Z,7Z,10Z,13Z,16Z)/P-18:0) having positive correlations with the expression level of novel-89-mature (Fig. 4), were statistically and theoretically in accordance with the process of metabolism in intro [228], validating the regulation of DEMs.

\section{Conclusion}

Taking all the findings together, we propose that QFPDD can modify immunity, inflammation, virus infection, pulmonary fibrosis through the regulation of miRNAs to improve treatment outcomes of COVID-19 (Fig. 5). The regulation of miRNAs was partly validated by change of substrates (PCs) and product (phosphorylcholine) of a core target gene, Phospholipase C, gamma 1 (Plcg1).

\section{Declarations}

\section{Acknowledgments}

The ideas presented here were developed during completion of research projects funded by the Jiangxi Emergency Research Project TCM Application for COVID-19 Prevention and Treatment (NO. 2020 J001). This project was financially supported by Jaingxi University of Chinese Medicine. The funder had no role in study design, data collection and analysis, decision to publish, or preparation of the manuscript.

\section{Authors' contributions}

Conceptualization and formal analysis: Tie-Long Xu.

Rats rearing \& Sample Collection: Longxue Li, Zhiyong Liu, Yuran Chen, Liming Luo, Yumeng Peng, Yangqing Zeng, Qingni $\mathrm{Wu}, \mathrm{Hao}$ Chen

Supervision: Tie-Long Xu, Bin Zheng

Data analysis \& Writing-original draft: Tie-Long Xu, Longxue Li, Wei-qi Liu

\section{Funding}

Grants to Tie-Long Xu: Research Found of Jiangxi University of Chinese Medicine (NO. 5152000405).

\section{Ethics approval and consent to participate}

All rats were housed and handled according to the guidelines of the institutional and National Committees of Animal Use and Protection. All procedures were approved by the Animal Ethics Committee of Jiangxi University of Traditional Chinese Medicine, Nanchang, China (Permit Number: JZSYDWLL-20200920).

\section{Consent for publication}

Not applicable. 
Availability of data and materials

All relevant data are within the paper and its Supporting Information files.

\section{Competing interests}

The authors declare that they have no competing interests.

\section{References}

1. Li Q, Lu H. Latest updates on COVID-19 vaccines, Biosci Trends 2021;14:463-466.

2. Fu R, Li J, Yu H et al. The Yin and Yang of traditional Chinese and Western medicine, Med Res Rev 2021.

3. Ren JL, Zhang AH, Wang XJ. Traditional Chinese medicine for COVID-19 treatment, Pharmacol Res 2020;155:104743.

4. Luo H, Gao Y, Zou J et al. Reflections on treatment of COVID-19 with traditional Chinese medicine, Chin Med 2020;15:94.

5. Wang Z, Yang L. Chinese herbal medicine: Fighting SARS-CoV-2 infection on all fronts, J Ethnopharmacol 2021;270:113869.

6. Liu M, Gao Y, Yuan Y et al. Efficacy and Safety of Integrated Traditional Chinese and Western Medicine for Corona Virus Disease 2019 (COVID-19): a systematic review and meta-analysis, Pharmacol Res 2020;158:104896.

7. Shi N, Liu B, Liang N et al. Association between early treatment with Qingfei Paidu decoction and favorable clinical outcomes in patients with COVID-19: A retrospective multicenter cohort study, Pharmacol Res 2020;161:105290.

8. Yang R, Liu H, Bai C et al. Chemical composition and pharmacological mechanism of Qingfei Paidu Decoction and Ma Xing Shi Gan Decoction against Coronavirus Disease 2019 (COVID-19): In silico and experimental study, Pharmacol Res 2020;157:104820.

9. Xin S, Cheng X, Zhu B et al. Clinical retrospective study on the efficacy of Qingfei Paidu decoction combined with Western medicine for COVID-19 treatment, Biomed Pharmacother 2020;129:110500.

10. Chen J, Wang YK, Gao Y et al. Protection against COVID-19 injury by qingfei paidu decoction via anti-viral, antiinflammatory activity and metabolic programming, Biomed Pharmacother 2020;129:110281.

11. Al-Romaima A, Liao Y, Feng J et al. Advances in the treatment of novel coronavirus disease (COVID-19) with Western medicine and traditional Chinese medicine: a narrative review, J Thorac Dis 2020;12:6054-6069.

12. Ren W, Ma Y, Wang R et al. Research Advance on Qingfei Paidu Decoction in Prescription Principle, Mechanism Analysis and Clinical Application, Front Pharmacol 2020;11:589714.

13. Niu W, Wu F, Cui H et al. Network Pharmacology Analysis to Identify Phytochemicals in Traditional Chinese Medicines That May Regulate ACE2 for the Treatment of COVID-19, Evid Based Complement Alternat Med 2020;2020:7493281.

14. Niu WH, Wu F, Cao WY et al. Network pharmacology for the identification of phytochemicals in traditional Chinese medicine for COVID-19 that may regulate interleukin-6, Biosci Rep 2021;41.

15. Samji P, Rajendran MK, Warrier VP et al. Regulation of Hippo signaling pathway in cancer: A MicroRNA perspective, Cell Signal 2021;78:109858.

16. He L, Hannon GJ. MicroRNAs: small RNAs with a big role in gene regulation, Nat Rev Genet 2004;5:522-531.

17. Berti FCB, Salviano-Silva A, Beckert HC et al. From squamous intraepithelial lesions to cervical cancer: Circulating microRNAs as potential biomarkers in cervical carcinogenesis, Biochim Biophys Acta Rev Cancer 2019;1872:188306.

18. Cipolla GA. A non-canonical landscape of the microRNA system, Front Genet 2014;5:337.

19. Xu TL, Sun YW, Feng XY et al. Development of miRNA-Based Approaches to Explore the Interruption of MosquitoBorne Disease Transmission, Front Cell Infect Microbiol 2021;11:665444. 
20. Sun J, Li M, Li Z et al. Identification and profiling of conserved and novel microRNAs from Chinese Qinchuan bovine longissimus thoracis, BMC Genomics 2013;14:42.

21. Sardar R, Satish D, Gupta D. Identification of Novel SARS-CoV-2 Drug Targets by Host MicroRNAs and Transcription Factors Co-regulatory Interaction Network Analysis, Front Genet 2020;11:571274.

22. Wicik Z, Eyileten C, Jakubik D et al. ACE2 Interaction Networks in COVID-19: A Physiological Framework for Prediction of Outcome in Patients with Cardiovascular Risk Factors, J Clin Med 2020;9.

23. Bardin P, Marchal-Duval E, Sonneville F et al. Small RNA and transcriptome sequencing reveal the role of miR-199a-3p in inflammatory processes in cystic fibrosis airways, J Pathol 2018;245:410-420.

24. Snyder-Talkington BN, Dong C, Sargent LM et al. mRNAs and miRNAs in whole blood associated with lung hyperplasia, fibrosis, and bronchiolo-alveolar adenoma and adenocarcinoma after multi-walled carbon nanotube inhalation exposure in mice, J Appl Toxicol 2016;36:161-174.

25. Savary G, Dewaeles E, Diazzi S et al. The Long Noncoding RNA DNM30S Is a Reservoir of FibromiRs with Major Functions in Lung Fibroblast Response to TGF-beta and Pulmonary Fibrosis, Am J Respir Crit Care Med 2019;200:184198.

26. Xie W, Lu Q, Wang K et al. miR-34b-5p inhibition attenuates lung inflammation and apoptosis in an LPS-induced acute lung injury mouse model by targeting progranulin, J Cell Physiol 2018;233:6615-6631.

27. Hu RP, Lu YY, Zhang XJ. MiR-34b-5p knockdown attenuates bleomycin-induced pulmonary fibrosis by targeting tissue inhibitor of metalloproteinase 3 (TIMP3), Eur Rev Med Pharmacol Sci 2019;23:2273-2279.

28. Teodori L, Costa A, Campanella L et al. Skeletal Muscle Atrophy in Simulated Microgravity Might Be Triggered by Immune-Related microRNAs, Front Physiol 2018;9:1926.

29. Li Y, Tan W, Ye F et al. Inflammation as a risk factor for stroke in atrial fibrillation: data from a microarray data analysis, J Int Med Res 2020;48:300060520921671.

30. Li T, Wang X, Jing L et al. MiR-1-3p Inhibits Lung Adenocarcinoma Cell Tumorigenesis via Targeting Protein Regulator of Cytokinesis 1, Front Oncol 2019;9:120.

31. Zhao P, Zhu Y, Sun L et al. Circulating Exosomal miR-1-3p from Rats with Myocardial Infarction Plays a Protective Effect on Contrast-Induced Nephropathy via Targeting ATG13 and activating the AKT Signaling Pathway, Int J Biol Sci 2021;17:972-985.

32. Li L, Ma X, Zhao YF et al. MiR-1-3p facilitates Th17 differentiation associating with multiple sclerosis via targeting ETS1, Eur Rev Med Pharmacol Sci 2020;24:6881-6892.

33. Scolari FL, Faganello LS, Garbin HI et al. A systematic review of microRNAs in patients with hypertrophic cardiomyopathy, Int J Cardiol 2021;327:146-154.

34. Peng S, Wang J, Wei S et al. Endogenous Cellular MicroRNAs Mediate Antiviral Defense against Influenza A Virus, Mol Ther Nucleic Acids 2018;10:361-375.

35. Sarma A, Phukan $\mathrm{H}$, Halder $\mathrm{N}$ et al. An in-silico approach to study the possible interactions of miRNA between human and SARS-CoV2, Comput Biol Chem 2020;88:107352.

36. Duy J, Honko AN, Altamura LA et al. Virus-encoded miRNAs in Ebola virus disease, Sci Rep 2018;8:6480.

37. Zhang $X$, Zheng $Y$, Jagadeeswaran $G$ et al. Identification of conserved and novel microRNAs in Manduca sexta and their possible roles in the expression regulation of immunity-related genes, Insect Biochem Mol Biol 2014;47:12-22.

38. Tsukerman P, Enk J, Mandelboim O. Metastamir-mediated immune evasion: miR-10b downregulates the stressinduced molecule MICB, hence avoid recognition by NKG2D receptor, Oncoimmunology 2013;2:e22245.

39. Papadaki C, Thomopoulou K, Monastirioti A et al. MicroRNAs Regulating Tumor and Immune Cell Interactions in the Prediction of Relapse in Early Stage Breast Cancer, Biomedicines 2021;9. 
40. de Oliveira PSN, Coutinho LL, Cesar ASM et al. Co-Expression Networks Reveal Potential Regulatory Roles of miRNAs in Fatty Acid Composition of Nelore Cattle, Front Genet 2019;10:651.

41. Singh AK, Rooge SB, Varshney A et al. Global microRNA expression profiling in the liver biopsies of hepatitis B virusinfected patients suggests specific microRNA signatures for viral persistence and hepatocellular injury, Hepatology 2018;67:1695-1709.

42. Huang J, Liang Z, Yang B et al. Derepression of microRNA-mediated protein translation inhibition by apolipoprotein B mRNA-editing enzyme catalytic polypeptide-like $3 \mathrm{G}$ (APOBEC3G) and its family members, J Biol Chem 2007;282:33632-33640.

43. Hoshina S, Sekizuka T, Kataoka M et al. Profile of Exosomal and Intracellular microRNA in Gamma-HerpesvirusInfected Lymphoma Cell Lines, PLoS One 2016;11:e0162574.

44. Li G, Wu Z, Peng Y et al. MicroRNA-10b induced by Epstein-Barr virus-encoded latent membrane protein-1 promotes the metastasis of human nasopharyngeal carcinoma cells, Cancer Lett 2010;299:29-36.

45. Halappanavar S, Wu D, Williams A et al. Pulmonary gene and microRNA expression changes in mice exposed to benzo(a)pyrene by oral gavage, Toxicology 2011;285:133-141.

46. Su A, Zhou Y, Guo Y et al. Identification and expression analysis of MicroRNAs in chicken spleen in a corticosteroneinduced stress model, Res Vet Sci 2021;136:287-296.

47. Qiu N, Xu X, He Y. LncRNA TUG1 alleviates sepsis-induced acute lung injury by targeting miR-34b-5p/GAB1, BMC Pulm Med 2020;20:49.

48. Zheng C, Wu D, Shi S et al. miR-34b-5p promotes renal cell inflammation and apoptosis by inhibiting aquaporin-2 in sepsis-induced acute kidney injury, Ren Fail 2021;43:291-301.

49. Yang C, Lu W, He H et al. Inflammation and DNA Methylation-Dependent Down-Regulation of miR-34b-5p Mediates cMYC Expression and CRL4(DCAF4) E3 Ligase Activity in Colitis-Associated Cancer, Am J Pathol 2020;190:674-688.

50. Du X, Yang Y, Xiao G et al. Respiratory syncytial virus infection-induced mucus secretion by down-regulation of miR34b/c-5p expression in airway epithelial cells, J Cell Mol Med 2020;24:12694-12705.

51. Li Z, Luo Q, Xu H et al. MiR-34b-5p Suppresses Melanoma Differentiation-Associated Gene 5 (MDA5) Signaling Pathway to Promote Avian Leukosis Virus Subgroup J (ALV-J)-Infected Cells Proliferaction and ALV-J Replication, Front Cell Infect Microbiol 2017;7:17.

52. Aungier SR, Ohmori $\mathrm{H}$, Clinton $\mathrm{M}$ et al. MicroRNA-100-5p indirectly modulates the expression of II6, Ptgs $1 / 2$ and TIr4 mRNA in the mouse follicular dendritic cell-like cell line, FL-Y, Immunology 2015;144:34-44.

53. Assmann TS, Recamonde-Mendoza M, De Souza BM et al. MicroRNA expression profiles and type 1 diabetes mellitus: systematic review and bioinformatic analysis, Endocr Connect 2017;6:773-790.

54. Li Y, Yang YY, Ren JL et al. Exosomes secreted by stem cells from human exfoliated deciduous teeth contribute to functional recovery after traumatic brain injury by shifting microglia M1/M2 polarization in rats, Stem Cell Res Ther 2017;8:198.

55. Strycharz J, Wroblewski A, Zieleniak A et al. Visceral Adipose Tissue of Prediabetic and Diabetic Females Shares a Set of Similarly Upregulated microRNAs Functionally Annotated to Inflammation, Oxidative Stress and Insulin Signaling, Antioxidants (Basel) 2021;10.

56. Hromadnikova I, Kotlabova K, Krofta L. A History of Preterm Delivery Is Associated with Aberrant Postpartal MicroRNA Expression Profiles in Mothers with an Absence of Other Pregnancy-Related Complications, Int J Mol Sci 2021;22.

57. Ninomiya M, Kondo Y, Kimura $\mathrm{O}$ et al. The expression of miR-125b-5p is increased in the serum of patients with chronic hepatitis B infection and inhibits the detection of hepatitis B virus surface antigen, J Viral Hepat 2016;23:330339.

58. Choi EJ, Kim HB, Baek YH et al. Differential microRNA expression following infection with a mouse-adapted, highly virulent avian H5N2 virus, BMC Microbiol 2014;14:252. 
59. Mishima S, Kashiwakura JI, Toyoshima S et al. Higher PGD2 production by synovial mast cells from rheumatoid arthritis patients compared with osteoarthritis patients via miR-199a-3p/prostaglandin synthetase 2 axis, Sci Rep $2021 ; 11: 5738$.

60. Haralambieva IH, Kennedy RB, Simon WL et al. Differential miRNA expression in B cells is associated with interindividual differences in humoral immune response to measles vaccination, PLoS One 2018;13:e0191812.

61. Xiong A, Wang J, Mao XL et al. MiR-199a-3p modulates the function of dendritic cells involved in transplantation tolerance by targeting CD86, HLA 2019;94:493-503.

62. Peng J, Jiang J, Wang $\mathrm{H}$ et al. miR199a3p suppresses cervical epithelial cell inflammation by inhibiting the HMGB1/TLR4/NFkappaB pathway in preterm birth, Mol Med Rep 2020;22:926-938.

63. Zhang R, Qin L, Shi J. MicroRNA199a3p suppresses high glucoseinduced apoptosis and inflammation by regulating the IKKbeta/NFkappaB signaling pathway in renal tubular epithelial cells, Int J Mol Med 2020;46:2161-2171.

64. Xue Y, Zeng G, Cheng J et al. Engineered macrophage membrane-enveloped nanomedicine for ameliorating myocardial infarction in a mouse model, Bioeng Transl Med 2021;6:e10197.

65. Zhang H, Zhang F, Li W. Function of intestinal barrier protected by regulating the miR-199a-3p in ulcerative colitis: Modulation of IL-23/IL-17A axis, Fundam Clin Pharmacol 2021.

66. Yang R, Xu X, Li H et al. p53 induces miR199a-3p to suppress SOCS7 for STAT3 activation and renal fibrosis in UUO, Sci Rep 2017;7:43409.

67. Orr C, Myers R, Li B et al. Longitudinal analysis of serum microRNAs as predictors of cirrhosis regression during treatment of hepatitis B virus infection, Liver Int 2020;40:1693-1700.

68. Lee CG, Kim YW, Kim EH et al. Farnesoid X receptor protects hepatocytes from injury by repressing miR-199a-3p, which increases levels of LKB1, Gastroenterology 2012;142:1206-1217 e1207.

69. Cabantous S, Hou X, Louis L et al. Evidence for an important role of host microRNAs in regulating hepatic fibrosis in humans infected with Schistosoma japonicum, Int J Parasitol 2017;47:823-830.

70. Yang X, Ma L, Wei R et al. Twist1-induced miR-199a-3p promotes liver fibrosis by suppressing caveolin-2 and activating TGF-beta pathway, Signal Transduct Target Ther 2020;5:75.

71. Santhakumar D, Forster T, Laqtom NN et al. Combined agonist-antagonist genome-wide functional screening identifies broadly active antiviral microRNAs, Proc Natl Acad Sci U S A 2010;107:13830-13835.

72. El-Guendy NM, Helwa R, El-Halawany MS et al. The Liver MicroRNA Expression Profiles Associated With Chronic Hepatitis C Virus (HCV) Genotype-4 Infection: A Preliminary Study, Hepat Mon 2016;16:e33881.

73. Zhen Y, Wang F, Liang W et al. Identification of Differentially Expressed Non-coding RNA in Porcine Alveolar Macrophages from Tongcheng and Large White Pigs Responded to PRRSV, Sci Rep 2018;8:15621.

74. Dong KS, Chen Y, Yang G et al. TGF-beta1 accelerates the hepatitis B virus X-induced malignant transformation of hepatic progenitor cells by upregulating miR-199a-3p, Oncogene 2020;39:1807-1820.

75. Xiao P, Sun S, Cao J et al. Expression profile of microRNAs in bronchoalveolar lavage fluid of rats as predictors for smoke inhalation injury, Burns 2018;44:2042-2050.

76. Lu Q, Sun Y, Duan Y et al. Comprehensive microRNA profiling reveals potential augmentation of the IL1 pathway in rheumatic heart valve disease, BMC Cardiovasc Disord 2018;18:53.

77. Yeh DW, Chen YS, Lai CY et al. Downregulation of COMMD1 by miR-205 promotes a positive feedback loop for amplifying inflammatory- and stemness-associated properties of cancer cells, Cell Death Differ 2016;23:841-852.

78. Chen B, Li Y, Liu Y et al. circLRP6 regulates high glucose-induced proliferation, oxidative stress, ECM accumulation, and inflammation in mesangial cells, J Cell Physiol 2019;234:21249-21259.

79. Lee YS, Han SB, Ham HJ et al. IL-32gamma suppressed atopic dermatitis through inhibition of miR-205 expression via inactivation of nuclear factor-kappa B, J Allergy Clin Immunol 2020;146:156-168.

Page $17 / 29$ 
80. Sun B, Xu S, Yan Y et al. miR-205 Suppresses Pulmonary Fibrosis by Targeting GATA3 Through Inhibition of Endoplasmic Reticulum Stress, Curr Pharm Biotechnol 2020;21:720-726.

81. Igietseme JU, Omosun Y, Stuchlik O et al. Role of Epithelial-Mesenchyme Transition in Chlamydia Pathogenesis, PLoS One 2015;10:e0145198.

82. Xiao Z, Reddy DPK, Xue C et al. Profiling of miR-205/P4HA3 Following Angiotensin II-Induced Atrial Fibrosis: Implications for Atrial Fibrillation, Front Cardiovasc Med 2021;8:609300.

83. Cui M, Xiao Z, Sun B et al. Involvement of cholesterol in hepatitis B virus X protein-induced abnormal lipid metabolism of hepatoma cells via up-regulating miR-205-targeted ACSL4, Biochem Biophys Res Commun 2014;445:651-655.

84. Motsch N, Alles J, Imig J et al. MicroRNA profiling of Epstein-Barr virus-associated NK/T-cell lymphomas by deep sequencing, PLoS One 2012;7:e42193.

85. Zhang T, Zhang J, Cui $M$ et al. Hepatitis B virus $X$ protein inhibits tumor suppressor miR-205 through inducing hypermethylation of miR-205 promoter to enhance carcinogenesis, Neoplasia 2013;15:1282-1291.

86. Wang Y, Gao Y, Shi W et al. Profiles of differential expression of circulating microRNAs in hepatitis B virus-positive small hepatocellular carcinoma, Cancer Biomark 2015;15:171-180.

87. Martinez-Gonzalez E, Brochado-Kith O, Gomez-Sanz A et al. Comparison of methods and characterization of small RNAs from plasma extracellular vesicles of HIV/HCV coinfected patients, Sci Rep 2020;10:11140.

88. Cohen JL, Ata AE, Jackson NL et al. Differential stress induced c-Fos expression and identification of region-specific miRNA-mRNA networks in the dorsal raphe and amygdala of high-responder/low-responder rats, Behav Brain Res 2017;319:110-123.

89. Sun L, Guo Y, He P et al. Genome-wide profiling of long noncoding RNA expression patterns and CeRNA analysis in mouse cortical neurons infected with different strains of borna disease virus, Genes Dis 2019;6:147-158.

90. Eroglu F, Dokur M, Ulu Y. MicroRNA profile in immune response of alveolar and cystic echinococcosis patients, Parasite Immunol 2021;43:e12817.

91. Yan Z, Zang B, Gong X et al. MiR-214-3p exacerbates kidney damages and inflammation induced by hyperlipidemic pancreatitis complicated with acute renal injury, Life Sci 2020;241:117118.

92. Zhuang JB, Li T, Hu XM et al. Circ_CHFR expedites cell growth, migration and inflammation in ox-LDL-treated human vascular smooth muscle cells via the miR-214-3p/Wnt3/beta-catenin pathway, Eur Rev Med Pharmacol Sci 2020;24:3282-3292.

93. Yang F, Qin Y, Lv J et al. Silencing long non-coding RNA Kcnq1 ot1 alleviates pyroptosis and fibrosis in diabetic cardiomyopathy, Cell Death Dis 2018;9:1000.

94. Li JA, Wang YD, Wang K et al. Downregulation of miR-214-3p May Contribute to Pathogenesis of Ulcerative Colitis via Targeting STAT6, Biomed Res Int 2017;2017:8524972.

95. Qi Y, Wu H, Mai C et al. LncRNA-MIAT-Mediated miR-214-3p Silencing Is Responsible for IL-17 Production and Cardiac Fibrosis in Diabetic Cardiomyopathy, Front Cell Dev Biol 2020;8:243.

96. Chouvarine P, Legchenko E, Geldner J et al. Hypoxia drives cardiac miRNAs and inflammation in the right and left ventricle, J Mol Med (Berl) 2019;97:1427-1438.

97. Deshpande RP, Panigrahi M, Y BVKC et al. Profiling of microRNAs modulating cytomegalovirus infection in astrocytoma patients, Neurol Sci 2018;39:1895-1902.

98. Lian Z, Lv FF, Yu J et al. The anti-inflammatory effect of microRNA-383-3p interacting with IL1R2 against homocysteine-induced endothelial injury in rat coronary arteries, J Cell Biochem 2018;119:6684-6694.

99. Chao MW, Yang CH, Lin PT et al. Exposure to PM2.5 causes genetic changes in fetal rat cerebral cortex and hippocampus, Environ Toxicol 2017;32:1412-1425.

100. Tanner JE, Alfieri C. The Fatty Acid Lipid Metabolism Nexus in COVID-19, Viruses 2021;13.

Page $18 / 29$ 
101. Zhang Y, Sun H, Pei R et al. The SARS-CoV-2 protein ORF3a inhibits fusion of autophagosomes with lysosomes, Cell Discov 2021;7:31.

102. Miao G, Zhao H, Li Y et al. ORF3a of the COVID-19 virus SARS-CoV-2 blocks HOPS complex-mediated assembly of the SNARE complex required for autolysosome formation, Dev Cell 2021;56:427-442 e425.

103. Yu L, Liu X, Yu X. ADP-ribosylhydrolases: from DNA damage repair to COVID-19, J Zhejiang Univ Sci B 2021;22:21-30.

104. Camargo SMR, Vuille-Dit-Bille RN, Meier CF et al. ACE2 and gut amino acid transport, Clin Sci (Lond) 2020;134:28232833.

105. Gupta R, Charron J, Stenger CL et al. SARS-CoV-2 (COVID-19) structural and evolutionary dynamicome: Insights into functional evolution and human genomics, J Biol Chem 2020;295:11742-11753.

106. Yan R, Zhang Y, Li Y et al. Structural basis for the recognition of SARS-CoV-2 by full-length human ACE2, Science 2020;367:1444-1448.

107. Postlethwait JH, Massaquoi MS, Farnsworth DR et al. The SARS-CoV-2 receptor and other key components of the Renin-Angiotensin-Aldosterone System related to COVID-19 are expressed in enterocytes in larval zebrafish, Biol Open 2021;10.

108. Ferreira-Duarte M, Estevinho MM, Duarte-Araujo M et al. Unraveling the Role of ACE2, the Binding Receptor for SARSCoV-2, in Inflammatory Bowel Disease, Inflamm Bowel Dis 2020;26:1787-1795.

109. Anand P, Puranik A, Aravamudan M et al. SARS-CoV-2 strategically mimics proteolytic activation of human ENaC, Elife 2020;9.

110. Severe Covid GG, Ellinghaus D, Degenhardt F et al. Genomewide Association Study of Severe Covid-19 with Respiratory Failure, N Engl J Med 2020;383:1522-1534.

111. Hoel H, Heggelund L, Reikvam DH et al. Elevated markers of gut leakage and inflammasome activation in COVID-19 patients with cardiac involvement, J Intern Med 2021;289:523-531.

112. Arai Y, Asano K, Mandai S et al. WNK1-TAK1 signaling suppresses lipopolysaccharide-induced cytokine production and classical activation in macrophages, Biochem Biophys Res Commun 2020;533:1290-1297.

113. Gentzsch M, Rossier BC. A Pathophysiological Model for COVID-19: Critical Importance of Transepithelial Sodium Transport upon Airway Infection, Function (Oxf) 2020;1:zqaa024.

114. Kothari $\mathrm{H}$, Williams $\mathrm{CM}$, McSkimming $\mathrm{C}$ et al. Identification of human immune cell subtypes most responsive to IL1beta-induced inflammatory signaling using mass cytometry, Sci Signal 2021;14.

115. Kusnadi A, Ramirez-Suastegui C, Fajardo V et al. Severely ill COVID-19 patients display impaired exhaustion features in SARS-CoV-2-reactive CD8(+) T cells, Sci Immunol 2021;6.

116. Yin X, Riva L, Pu Y et al. MDA5 Governs the Innate Immune Response to SARS-CoV-2 in Lung Epithelial Cells, Cell Rep 2021;34:108628.

117. Sur S, Khatun M, Steele R et al. Exosomes from COVID-19 Patients Carry Tenascin-C and Fibrinogen-beta in Triggering Inflammatory Signals in Cells of Distant Organ, Int J Mol Sci 2021;22.

118. Li H, Quan J, Zhao X et al. USP14 negatively regulates RIG-I-mediated IL-6 and TNF-alpha production by inhibiting NFkappaB activation, Mol Immunol 2021;130:69-76.

119. Hariharan A, Hakeem AR, Radhakrishnan S et al. The Role and Therapeutic Potential of NF-kappa-B Pathway in Severe COVID-19 Patients, Inflammopharmacology 2021;29:91-100.

120. Crooke PS, 3rd, Tossberg JT, Porter KP et al. Cutting Edge: Reduced Adenosine-to-Inosine Editing of Endogenous Alu RNAs in Severe COVID-19 Disease, J Immunol 2021;206:1691-1696.

121. Cui $Y$, Xin $H$, Tao $Y$ et al. Arenaria kansuensis attenuates pulmonary fibrosis in mice via the activation of Nrf2 pathway and the inhibition of NF-kB/TGF-beta1/Smad2/3 pathway, Phytother Res 2021;35:974-986. 
122. Ma QH, Ren MY, Luo JB. San Wu Huangqin decoction regulates inflammation and immune dysfunction induced by influenza virus by regulating the NF-kappaB signaling pathway in $\mathrm{H} 1 \mathrm{~N} 1$-infected mice, J Ethnopharmacol 2021;264:112800.

123. Carcaterra M, Caruso C. Alveolar epithelial cell type II as main target of SARS-CoV-2 virus and COVID-19 development via NF-Kb pathway deregulation: A physio-pathological theory, Med Hypotheses 2021;146:110412.

124. Wu J, Shi Y, Pan X et al. SARS-CoV-2 ORF9b inhibits RIG-I-MAVS antiviral signaling by interrupting K63-linked ubiquitination of NEMO, Cell Rep 2021;34:108761.

125. Wang M, Fu D, Yao L et al. Theoretical Study of the Molecular Mechanism of Maxingyigan Decoction Against COVID19: Network Pharmacology-based Strategy, Comb Chem High Throughput Screen 2021;24:294-305.

126. Han K, Blair RV, Iwanaga $\mathrm{N}$ et al. Lung Expression of Human Angiotensin-Converting Enzyme 2 Sensitizes the Mouse to SARS-CoV-2 Infection, Am J Respir Cell Mol Biol 2021;64:79-88.

127. Wu F, Lu F, Fan X et al. Immune-related miRNA-mRNA regulation network in the livers of DHAV-3-infected ducklings, BMC Genomics 2020;21:123.

128. Chen S. Identification of SARS-CoV-2 Proteins Binding Human mRNAs As a Novel Signature Predicting Overall Survival in Hepatocellular Carcinoma, DNA Cell Biol 2021;40:359-372.

129. Cruz-Pulido D, Boley PA, Ouma WZ et al. Comparative Transcriptome Profiling of Human and Pig Intestinal Epithelial Cells after Porcine Deltacoronavirus Infection, Viruses 2021;13.

130. Fang C, Mei J, Tian H et al. CSF3 Is a Potential Drug Target for the Treatment of COVID-19, Front Physiol 2020;11:605792.

131. Qian Z, Zhang Z, Wang Y. T cell receptor signaling pathway and cytokine-cytokine receptor interaction affect the rehabilitation process after respiratory syncytial virus infection, PeerJ 2019;7:e7089.

132. Zhan Y, Yu S, Yang S et al. Newcastle Disease virus infection activates PI3K/Akt/mTOR and p38 MAPK/Mnk1 pathways to benefit viral mRNA translation via interaction of the viral NP protein and host elF4E, PLoS Pathog 2020;16:e1008610.

133. Saha A, Sharma AR, Bhattacharya M et al. Tocilizumab: A Therapeutic Option for the Treatment of Cytokine Storm Syndrome in COVID-19, Arch Med Res 2020;51:595-597.

134. Ma Q, Pan W, Li R et al. Liu Shen capsule shows antiviral and anti-inflammatory abilities against novel coronavirus SARS-CoV-2 via suppression of NF-kappaB signaling pathway, Pharmacol Res 2020;158:104850.

135. Zhu J, Ou L, Zhou Y et al. (-)-Epigallocatechin-3-gallate induces interferon-lambda2 expression to anti-influenza A virus in human bronchial epithelial cells (BEAS-2B) through p38 MAPK signaling pathway, J Thorac Dis 2020;12:989-997.

136. Hussman JP. Cellular and Molecular Pathways of COVID-19 and Potential Points of Therapeutic Intervention, Front Pharmacol 2020;11:1169.

137. Tao Q, Du J, Li X et al. Network pharmacology and molecular docking analysis on molecular targets and mechanisms of Huashi Baidu formula in the treatment of COVID-19, Drug Dev Ind Pharm 2020;46:1345-1353.

138. Duan C, Ge X, Wang J et al. Ergosterol peroxide exhibits antiviral and immunomodulatory abilities against porcine deltacoronavirus (PDCoV) via suppression of NF-kappaB and p38/MAPK signaling pathways in vitro, Int Immunopharmacol 2021;93:107317.

139. Yang X, Wang Y, Lu P et al. PEBP1 suppresses HIV transcription and induces latency by inactivating MAPK/NF-kappaB signaling, EMBO Rep 2020;21:e49305.

140. Mou Q, Jiang Y, Zhu L et al. EGCG induces beta-defensin 3 against influenza A virus H1N1 by the MAPK signaling pathway, Exp Ther Med 2020;20:3017-3024.

141. Zhu Z, Li W, Zhang X et al. Foot-and-Mouth Disease Virus Capsid Protein VP1 Interacts with Host Ribosomal Protein SA To Maintain Activation of the MAPK Signal Pathway and Promote Virus Replication, J Virol 2020;94. 
142. Grimes JM, Grimes KV. p38 MAPK inhibition: A promising therapeutic approach for COVID-19, J Mol Cell Cardiol 2020;144:63-65.

143. Liang $X$, Huang Y, Pan X et al. Erucic acid from Isatis indigotica Fort. suppresses influenza A virus replication and inflammation in vitro and in vivo through modulation of NF-kappaB and p38 MAPK pathway, J Pharm Anal 2020;10:130-146.

144. Botwina P, Owczarek K, Rajfur Z et al. Berberine Hampers Influenza A Replication through Inhibition of MAPK/ERK Pathway, Viruses 2020;12.

145. Zhang Z, Guo L, Lu X et al. Clinical analysis and pluripotent stem cells-based model reveal possible impacts of ACE2 and lung progenitor cells on infants vulnerable to COVID-19, Theranostics 2021;11:2170-2181.

146. Esmail S, Danter W. Viral pandemic preparedness: A pluripotent stem cell-based machine-learning platform for simulating SARS-CoV-2 infection to enable drug discovery and repurposing, Stem Cells Transl Med 2021;10:239-250.

147. Yiangou L, Davis RP, Mummery CL. Using Cardiovascular Cells from Human Pluripotent Stem Cells for COVID-19 Research: Why the Heart Fails, Stem Cell Reports 2021;16:385-397.

148. Tiwari SK, Wang S, Smith D et al. Revealing Tissue-Specific SARS-CoV-2 Infection and Host Responses using Human Stem Cell-Derived Lung and Cerebral Organoids, Stem Cell Reports 2021;16:437-445.

149. Marchiano S, Hsiang TY, Khanna A et al. SARS-CoV-2 Infects Human Pluripotent Stem Cell-Derived Cardiomyocytes, Impairing Electrical and Mechanical Function, Stem Cell Reports 2021;16:478-492.

150. Musial C, Gorska-Ponikowska M. Medical progress: Stem cells as a new therapeutic strategy for COVID-19, Stem Cell Res 2021;52:102239.

151. Kruger J, Gross R, Conzelmann C et al. Drug Inhibition of SARS-CoV-2 Replication in Human Pluripotent Stem CellDerived Intestinal Organoids, Cell Mol Gastroenterol Hepatol 2021;11:935-948.

152. Bojkova D, Wagner JUG, Shumliakivska M et al. SARS-CoV-2 infects and induces cytotoxic effects in human cardiomyocytes, Cardiovasc Res 2020;116:2207-2215.

153. Zahedi-Amiri A, Sequiera GL, Dhingra $S$ et al. Influenza a virus-triggered autophagy decreases the pluripotency of human-induced pluripotent stem cells, Cell Death Dis 2019;10:337.

154. Seif F, Aazami H, Khoshmirsafa M et al. JAK Inhibition as a New Treatment Strategy for Patients with COVID-19, Int Arch Allergy Immunol 2020;181:467-475.

155. Luo W, Li YX, Jiang LJ et al. Targeting JAK-STAT Signaling to Control Cytokine Release Syndrome in COVID-19, Trends Pharmacol Sci 2020;41:531-543.

156. Li Y, Chu F, Li P et al. Potential effect of Maxing Shigan decoction against coronavirus disease 2019 (COVID-19) revealed by network pharmacology and experimental verification, J Ethnopharmacol 2021;271:113854.

157. Yarmohammadi A, Yarmohammadi M, Fakhri S et al. Targeting pivotal inflammatory pathways in COVID-19: A mechanistic review, Eur J Pharmacol 2021;890:173620.

158. Lee S, Hirohama M, Noguchi M et al. Influenza A Virus Infection Triggers Pyroptosis and Apoptosis of Respiratory Epithelial Cells through the Type I Interferon Signaling Pathway in a Mutually Exclusive Manner, J Virol 2018;92.

159. Ding Y, Chen $L, W u$ W et al. Andrographolide inhibits influenza A virus-induced inflammation in a murine model through NF-kappaB and JAK-STAT signaling pathway, Microbes Infect 2017;19:605-615.

160. Li X, Qiu Q, Li M et al. Chemical composition and pharmacological mechanism of ephedra-glycyrrhiza drug pair against coronavirus disease 2019 (COVID-19), Aging (Albany NY) 2021;13:4811-4830.

161. Ahlers LRH, Trammell CE, Carrell GF et al. Insulin Potentiates JAK/STAT Signaling to Broadly Inhibit Flavivirus Replication in Insect Vectors, Cell Rep 2019;29:1946-1960 e1945.

162. Zhu X, Xie C, Li YM et al. TMEM2 inhibits hepatitis B virus infection in HepG2 and HepG2.2.15 cells by activating the JAK-STAT signaling pathway, Cell Death Dis 2016;7:e2239.

Page $21 / 29$ 
163. Solimani F, Meier K, Ghoreschi K. Janus kinase signaling as risk factor and therapeutic target for severe SARS-CoV-2 infection, Eur J Immunol 2021;51:1071-1075.

164. Aydemir MN, Aydemir HB, Korkmaz EM et al. Computationally predicted SARS-COV-2 encoded microRNAs target NFKB, JAK/STAT and TGFB signaling pathways, Gene Rep 2021;22:101012.

165. Singh MK, Mobeen A, Chandra A et al. A meta-analysis of comorbidities in COVID-19: Which diseases increase the susceptibility of SARS-CoV-2 infection?, Comput Biol Med 2021;130:104219.

166. Goker Bagca B, Biray Avci C. The potential of JAK/STAT pathway inhibition by ruxolitinib in the treatment of COVID-19, Cytokine Growth Factor Rev 2020;54:51-62.

167. McClain MT, Constantine FJ, Henao R et al. Dysregulated transcriptional responses to SARS-CoV-2 in the periphery, Nat Commun 2021;12:1079.

168. Khanmohammadi S, Rezaei N. Role of Toll-like receptors in the pathogenesis of COVID-19, J Med Virol 2021;93:27352739.

169. Abe T, Kaname Y, Hamamoto I et al. Hepatitis $C$ virus nonstructural protein $5 A$ modulates the toll-like receptor-MyD88dependent signaling pathway in macrophage cell lines, J Virol 2007;81:8953-8966.

170. Martin HJ, Lee JM, Walls $\mathrm{D}$ et al. Manipulation of the toll-like receptor 7 signaling pathway by Epstein-Barr virus, $\mathrm{J}$ Virol 2007;81:9748-9758.

171. Wong JP, Christopher ME, Viswanathan S et al. Activation of toll-like receptor signaling pathway for protection against influenza virus infection, Vaccine 2009;27:3481-3483.

172. Filippakis H, Spandidos DA, Sourvinos G. Herpesviruses: hijacking the Ras signaling pathway, Biochim Biophys Acta 2010;1803:777-785.

173. Filippakis H, Dimitropoulou P, Eliopoulos AG et al. The enhanced host-cell permissiveness of human cytomegalovirus is mediated by the Ras signaling pathway, Biochim Biophys Acta 2011;1813:1872-1882.

174. Stoppa G, Rumiato E, Saggioro D. Ras signaling contributes to survival of human T-cell leukemia/lymphoma virus type 1 (HTLV-1) Tax-positive T-cells, Apoptosis 2012;17:219-228.

175. Ishimaru H, Hosokawa K, Sugimoto A et al. MG132 exerts anti-viral activity against HSV-1 by overcoming virusmediated suppression of the ERK signaling pathway, Sci Rep 2020;10:6671.

176. Folgueira L, Algeciras A, MacMorran WS et al. The Ras-Raf pathway is activated in human immunodeficiency virusinfected monocytes and particpates in the activation of NF-kappa B, J Virol 1996;70:2332-2338.

177. Norman KL, Hirasawa K, Yang AD et al. Reovirus oncolysis: the Ras/RalGEF/p38 pathway dictates host cell permissiveness to reovirus infection, Proc Natl Acad Sci U S A 2004;101:11099-11104.

178. Kurbel S. The renin-angiotensin system in COVID-19: Why ACE2 targeting by coronaviruses produces higher mortality in elderly hypertensive patients?, Bioessays 2021;43:e2000112.

179. Pan W, Bodempudi V, Esfandyari T et al. Utilizing ras signaling pathway to direct selective replication of herpes simplex virus-1, PLoS One 2009;4:e6514.

180. Fujioka Y, Tsuda M, Hattori T et al. The Ras-PI3K signaling pathway is involved in clathrin-independent endocytosis and the internalization of influenza viruses, PLoS One 2011;6:e16324.

181. Suire S, Baltanas FC, Segonds-Pichon A et al. Frontline Science: TNF-alpha and GM-CSF1 priming augments the role of SOS1/2 in driving activation of Ras, PI3K-gamma, and neutrophil proinflammatory responses, J Leukoc Biol 2019;106:815-822.

182. Ouyang Y, Yin J, Wang W et al. Downregulated Gene Expression Spectrum and Immune Responses Changed During the Disease Progression in Patients With COVID-19, Clin Infect Dis 2020;71:2052-2060.

183. Chang YL, Ho BC, Sher S et al. miR-146a and miR-370 coordinate enterovirus 71-induced cell apoptosis through targeting SOS1 and GADD45beta, Cell Microbiol 2015;17:802-818.

Page $22 / 29$ 
184. Wu ZY, Li JR, Huang MH et al. Internal driving factors leading to extrahepatic manifestation of the hepatitis $\mathrm{C}$ virus infection, Int J Mol Med 2017;40:1792-1802.

185. Gao Q, Yang K, Chen D et al. Antifibrotic Potential of MiR-335-3p in Hereditary Gingival Fibromatosis, J Dent Res 2019;98:1140-1149.

186. Cheng J, Zhang J, Wu Z et al. Inferring microenvironmental regulation of gene expression from single-cell RNA sequencing data using scMLnet with an application to COVID-19, Brief Bioinform 2021;22:988-1005.

187. Burgel PR, Nadel JA. Epidermal growth factor receptor-mediated innate immune responses and their roles in airway diseases, Eur Respir J 2008;32:1068-1081.

188. Ho J, Yang X, Nikou SA et al. Candidalysin activates innate epithelial immune responses via epidermal growth factor receptor, Nat Commun 2019;10:2297.

189. Ommori R, Park K, Miyagawa F et al. Epidermal growth factor receptor (EGFR) inhibitory monoclonal antibodies and EGFR tyrosine kinase inhibitors have distinct effects on the keratinocyte innate immune response, $\mathrm{Br} \mathrm{J}$ Dermatol 2018;178:796-797.

190. Davies ER, Perotin JM, Kelly JFC et al. Involvement of the epidermal growth factor receptor in IL-13-mediated corticosteroid-resistant airway inflammation, Clin Exp Allergy 2020;50:672-686.

191. Pereira Beserra F, Sergio Gushiken LF, Vieira AJ et al. From Inflammation to Cutaneous Repair: Topical Application of Lupeol Improves Skin Wound Healing in Rats by Modulating the Cytokine Levels, NF-kappaB, Ki-67, Growth Factor Expression, and Distribution of Collagen Fibers, Int J Mol Sci 2020;21.

192. Asaro JA, Khan Z, Brewer M et al. Relationship Between Milk Fat Globule-Epidermal Growth Factor 8 and Intestinal Cytokines in Infants Born Preterm, J Pediatr 2021;230:71-75 e71.

193. Iwamoto M, Saso W, Nishioka K et al. The machinery for endocytosis of epidermal growth factor receptor coordinates the transport of incoming hepatitis B virus to the endosomal network, J Biol Chem 2020;295:800-807.

194. Iwamoto M, Saso W, Sugiyama R et al. Epidermal growth factor receptor is a host-entry cofactor triggering hepatitis B virus internalization, Proc Natl Acad Sci U S A 2019;116:8487-8492.

195. Kalinowski A, Galen BT, Ueki IF et al. Respiratory syncytial virus activates epidermal growth factor receptor to suppress interferon regulatory factor 1-dependent interferon-lambda and antiviral defense in airway epithelium, Mucosal Immunol 2018;11:958-967.

196. Saini S, Saini A, Thakur CJ et al. Genome-wide computational prediction of miRNAs in severe acute respiratory syndrome coronavirus 2 (SARS-CoV-2) revealed target genes involved in pulmonary vasculature and antiviral innate immunity, Mol Biol Res Commun 2020;9:83-91.

197. Hu W, Zhang S, Shen Y et al. Epidermal growth factor receptor is a co-factor for transmissible gastroenteritis virus entry, Virology 2018;521:33-43.

198. Zamanian Azodi M, Arjmand B, Zali A et al. Introducing APOA1 as a key protein in COVID-19 infection: a bioinformatics approach, Gastroenterol Hepatol Bed Bench 2020;13:367-373.

199. Vagapova ER, Lebedev TD, Prassolov VS. Viral fibrotic scoring and drug screen based on MAPK activity uncovers EGFR as a key regulator of COVID-19 fibrosis, Sci Rep 2021;11:11234.

200. Souchelnytskyi S, Nera A, Souchelnytskyi N. COVID-19 engages clinical markers for the management of cancer and cancer-relevant regulators of cell proliferation, death, migration, and immune response, Sci Rep 2021;11:5228.

201. Fang KY, Cao WC, Xie TA et al. Exploration and validation of related hub gene expression during SARS-CoV-2 infection of human bronchial organoids, Hum Genomics 2021;15:18.

202. Thornburg NJ, Raab-Traub N. Induction of epidermal growth factor receptor expression by Epstein-Barr virus latent membrane protein $1 \mathrm{C}$-terminal-activating region 1 is mediated by NF-kappaB p50 homodimer/Bcl-3 complexes, J Virol 2007;81:12954-12961.

Page 23/29 
203. Kung CP, Raab-Traub N. Epstein-Barr virus latent membrane protein 1 induces expression of the epidermal growth factor receptor through effects on Bcl-3 and STAT3, J Virol 2008;82:5486-5493.

204. Zheng WJ, Yan Q, Ni YS et al. Examining the effector mechanisms of Xuebijing injection on COVID-19 based on network pharmacology, BioData Min 2020;13:17.

205. Qin X, Huang C, Wu K et al. Anti-coronavirus disease 2019 (COVID-19) targets and mechanisms of puerarin, J Cell Mol Med 2021;25:677-685.

206. Kong Q, Wu Y, Gu Y et al. Analysis of the molecular mechanism of Pudilan (PDL) treatment for COVID-19 by network pharmacology tools, Biomed Pharmacother 2020;128:110316.

207. Venkataraman T, Frieman MB. The role of epidermal growth factor receptor (EGFR) signaling in SARS coronavirusinduced pulmonary fibrosis, Antiviral Res 2017;143:142-150.

208. Venkataraman T, Coleman CM, Frieman MB. Overactive Epidermal Growth Factor Receptor Signaling Leads to Increased Fibrosis after Severe Acute Respiratory Syndrome Coronavirus Infection, J Virol 2017;91.

209. Epstein Shochet G, Brook E, Eyal $O$ et al. Epidermal growth factor receptor paracrine upregulation in idiopathic pulmonary fibrosis fibroblasts is blocked by nintedanib, Am J Physiol Lung Cell Mol Physiol 2019;316:L1025-L1034.

210. Fujii T, Fuchs BC, Yamada S et al. Mouse model of carbon tetrachloride induced liver fibrosis: Histopathological changes and expression of CD133 and epidermal growth factor, BMC Gastroenterol 2010;10:79.

211. Yoshida N, Miyoshi H, Ohshima K. Clinical Applications of Genomic Alterations in ATLL: Predictive Markers and Therapeutic Targets, Cancers (Basel) 2021;13.

212. Zhang G, Xu S, Zhang Z et al. Identification of Key Genes and the Pathophysiology Associated With Major Depressive Disorder Patients Based on Integrated Bioinformatics Analysis, Front Psychiatry 2020;11:192.

213. Watanabe T. Adult T-cell leukemia: molecular basis for clonal expansion and transformation of HTLV-1-infected T cells, Blood 2017;129:1071-1081.

214. Kataoka K, Nagata Y, Kitanaka A et al. Integrated molecular analysis of adult T cell leukemia/lymphoma, Nat Genet 2015;47:1304-1315.

215. Yan L, Qu S, Liu G et al. Comparative Transcriptomic Analysis of Primary Duck Hepatocytes Provides Insight into Differential Susceptibility to DHBV Infection, PLoS One 2016;11:e0149702.

216. Liu Y, Wu H, Wang Z et al. Integrated expression profiles of mRNA and miRNA in a gerbil model of fatty liver fibrosis treated with exenatide, Clin Res Hepatol Gastroenterol 2021;45:101312.

217. Velazquez L, Gish GD, van Der Geer P et al. The shc adaptor protein forms interdependent phosphotyrosine-mediated protein complexes in mast cells stimulated with interleukin 3, Blood 2000;96:132-138.

218. Bone H, Welham MJ. Shc associates with the IL-3 receptor beta subunit, SHIP and Gab2 following IL-3 stimulation. Contribution of Shc PTB and SH2 domains, Cell Signal 2000;12:183-194.

219. Riegel K, Rajalingam K. The non-linearity of RAF-MEK signaling in dendritic cells, Cell Cycle 2020;19:2249-2259.

220. Riegel K, Schloder J, Sobczak M et al. RAF kinases are stabilized and required for dendritic cell differentiation and function, Cell Death Differ 2020;27:1300-1315.

221. Zhang Y, Pan X, Ran S et al. Purification, structural elucidation and anti-inflammatory activity in vitro of polysaccharides from Smilax china L, Int J Biol Macromol 2019;139:233-243.

222. Zhang X, Zhang N, Kan J et al. Anti-inflammatory activity of alkali-soluble polysaccharides from Arctium lappa L. and its effect on gut microbiota of mice with inflammation, Int J Biol Macromol 2020;154:773-787.

223. Liang S, Li X, Ma X et al. A flaxseed heteropolysaccharide stimulates immune responses and inhibits hepatitis B virus, Int J Biol Macromol 2019;136:230-240.

224. Fu Z, Xia L, De J et al. Beneficial effects on H1N1-induced acute lung injury and structure characterization of anticomplementary acidic polysaccharides from Juniperus pingii var. wilsonii, Int J Biol Macromol 2019;129:246-253. 
225. Ohta Y, Lee JB, Hayashi K et al. In vivo anti-influenza virus activity of an immunomodulatory acidic polysaccharide isolated from Cordyceps militaris grown on germinated soybeans, J Agric Food Chem 2007;55:10194-10199.

226. Dunn WB, Broadhurst D, Begley $P$ et al. Procedures for large-scale metabolic profiling of serum and plasma using gas chromatography and liquid chromatography coupled to mass spectrometry, Nat Protoc 2011;6:1060-1083.

227. Wiklund S, Johansson E, Sjostrom L et al. Visualization of GC/TOF-MS-based metabolomics data for identification of biochemically interesting compounds using OPLS class models, Anal Chem 2008;80:115-122.

228. Ramrakhiani L, Chand S. Recent progress on phospholipases: different sources, assay methods, industrial potential and pathogenicity, Appl Biochem Biotechnol 2011;164:991-1022.

229. Lu R, Zhao X, Li J et al. Genomic characterisation and epidemiology of 2019 novel coronavirus: implications for virus origins and receptor binding, Lancet 2020;395:565-574.

\section{Figures}

a

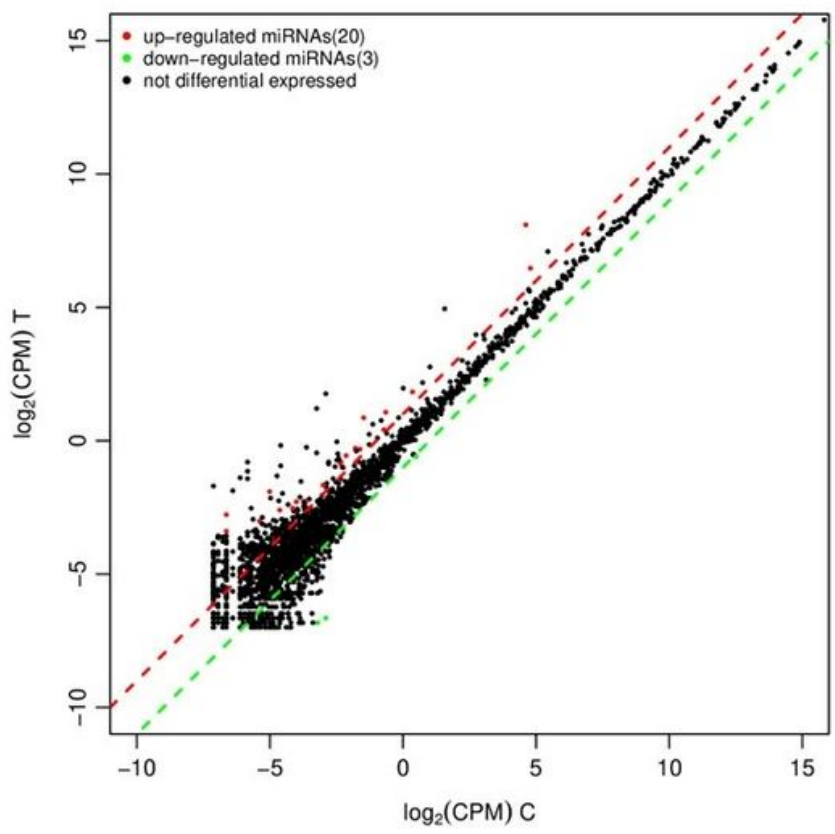

b

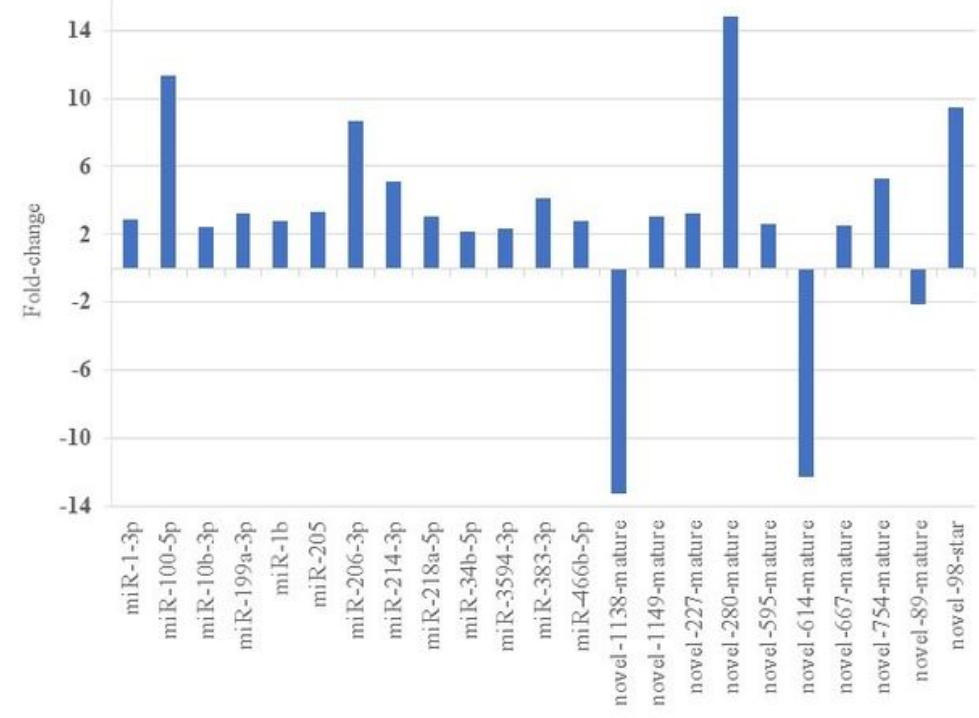

\section{Figure 1}

Differential expression of miRNAs in control and QFPDD treated Rats. a scatter plot of up- and down-regulated miRNAs in samples. Each point in the figure represents a miRNA. The $X$ and $Y$ axes show the expression levels in control or QFPDD treated samples. The red points represent statistically up-expressed miRNAs with a ratio $>2$, the black points represent equally expressed miRNAs with a ratio $\geq-2$ and $\leq 2$, and the green points represent down-expressed miRNAs with a ratio $<-2$. b screened significantly differentially expressed miRNAs between the plasmas of control and QFPDD treated rats. Ttests were used for the comparison of miRNAs expression. The P values were performed on the data with the significance threshold selected as 0.05 . 

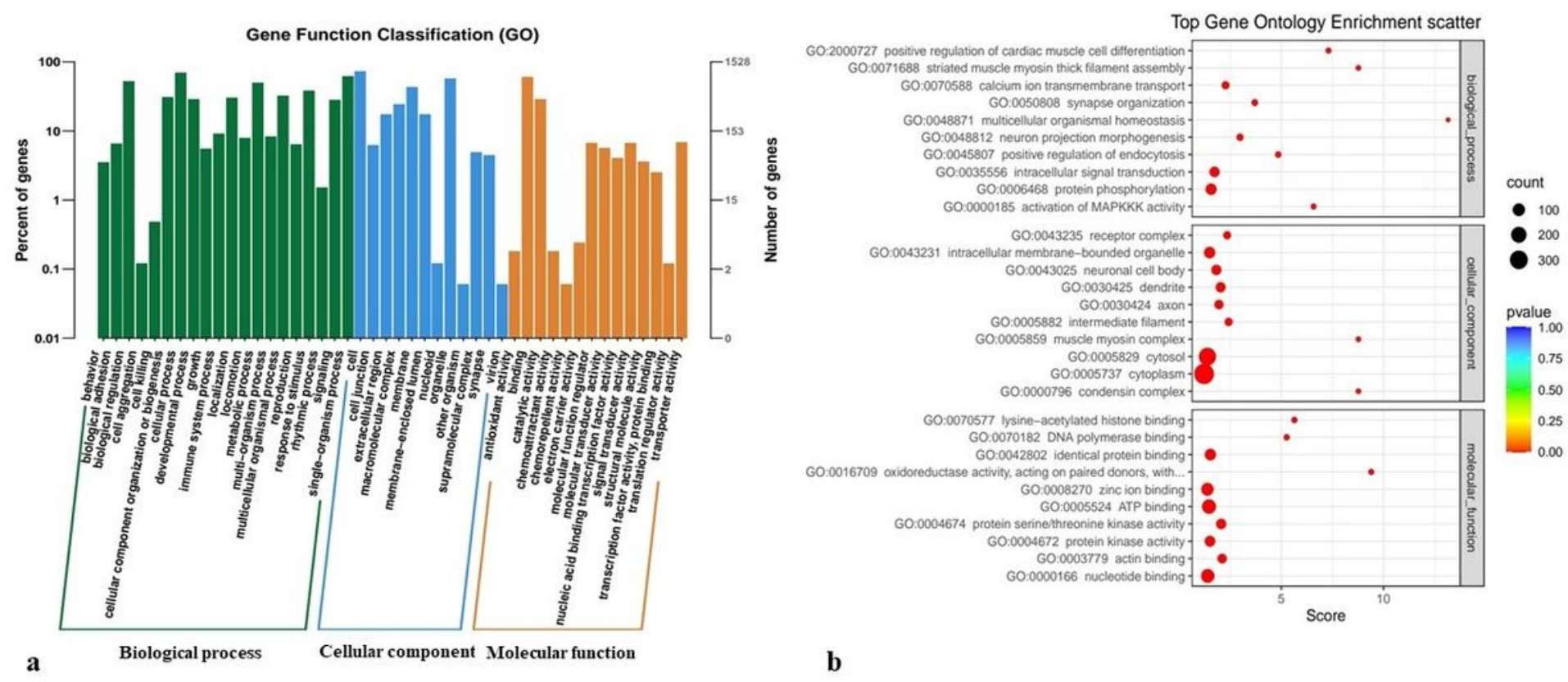

b

Figure 2

Overview of functions induced by GO enrichment analysis. a GO function classification. b top gene ontology enrichment scatter. 


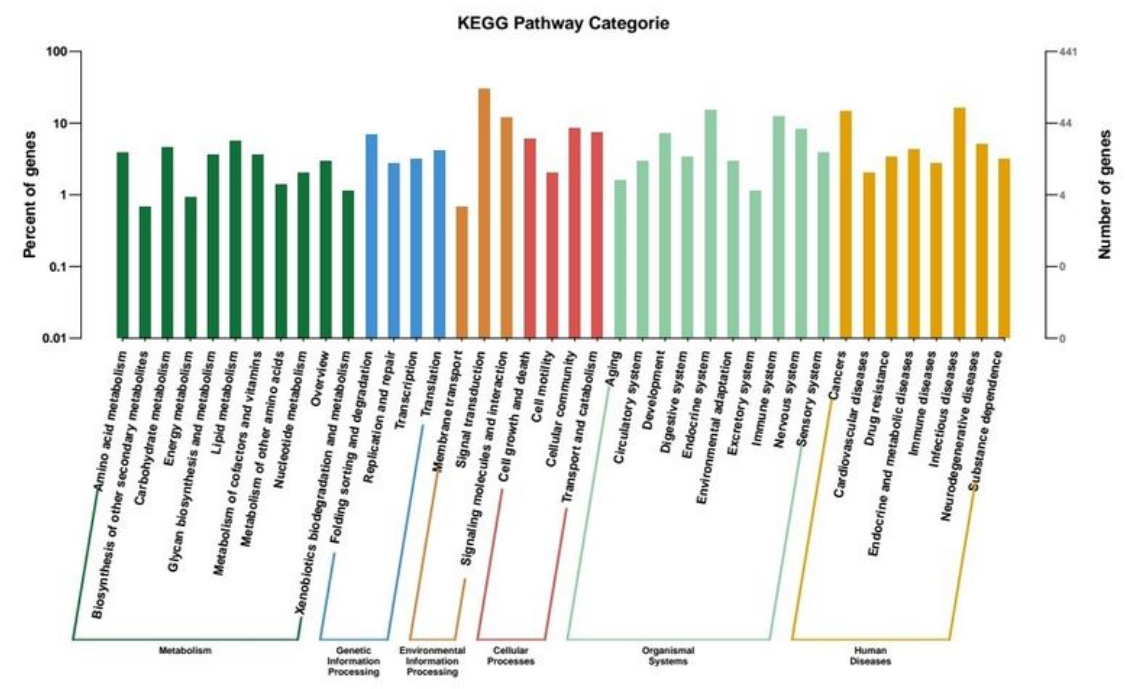

A

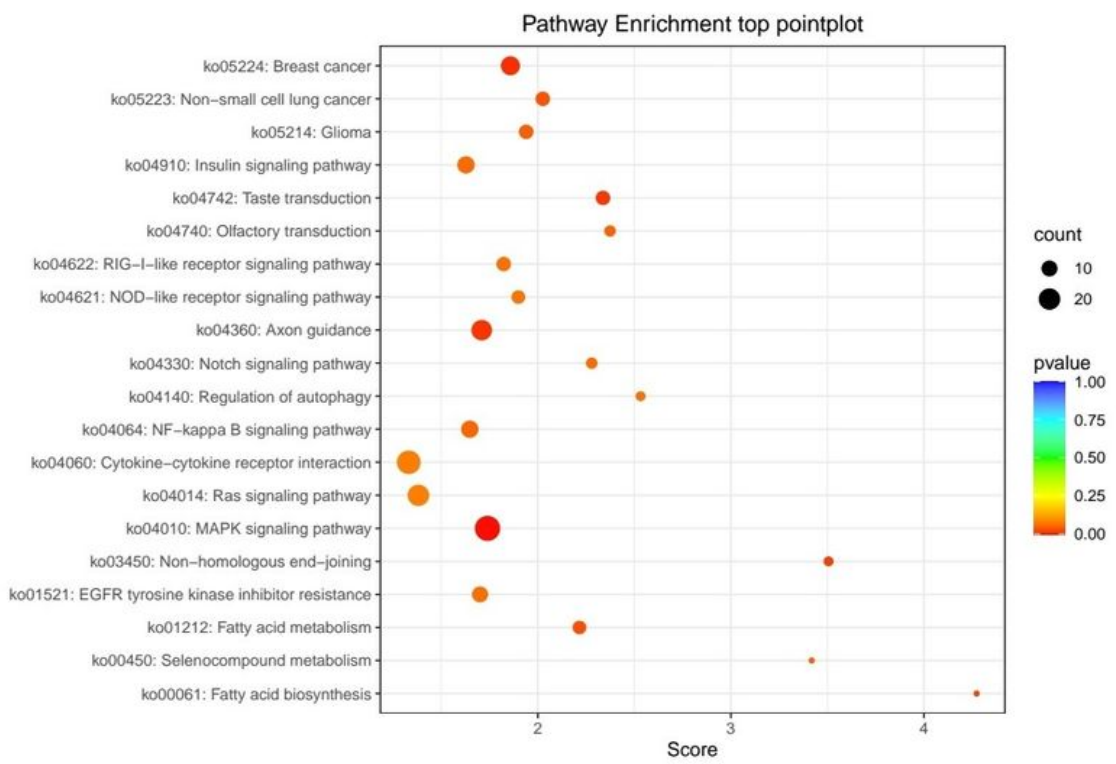

B

Figure 3

Overview of functions induced by GO enrichment analysis. a KEGG pathway categories. b KEGG pathway enrichment top point plot. 

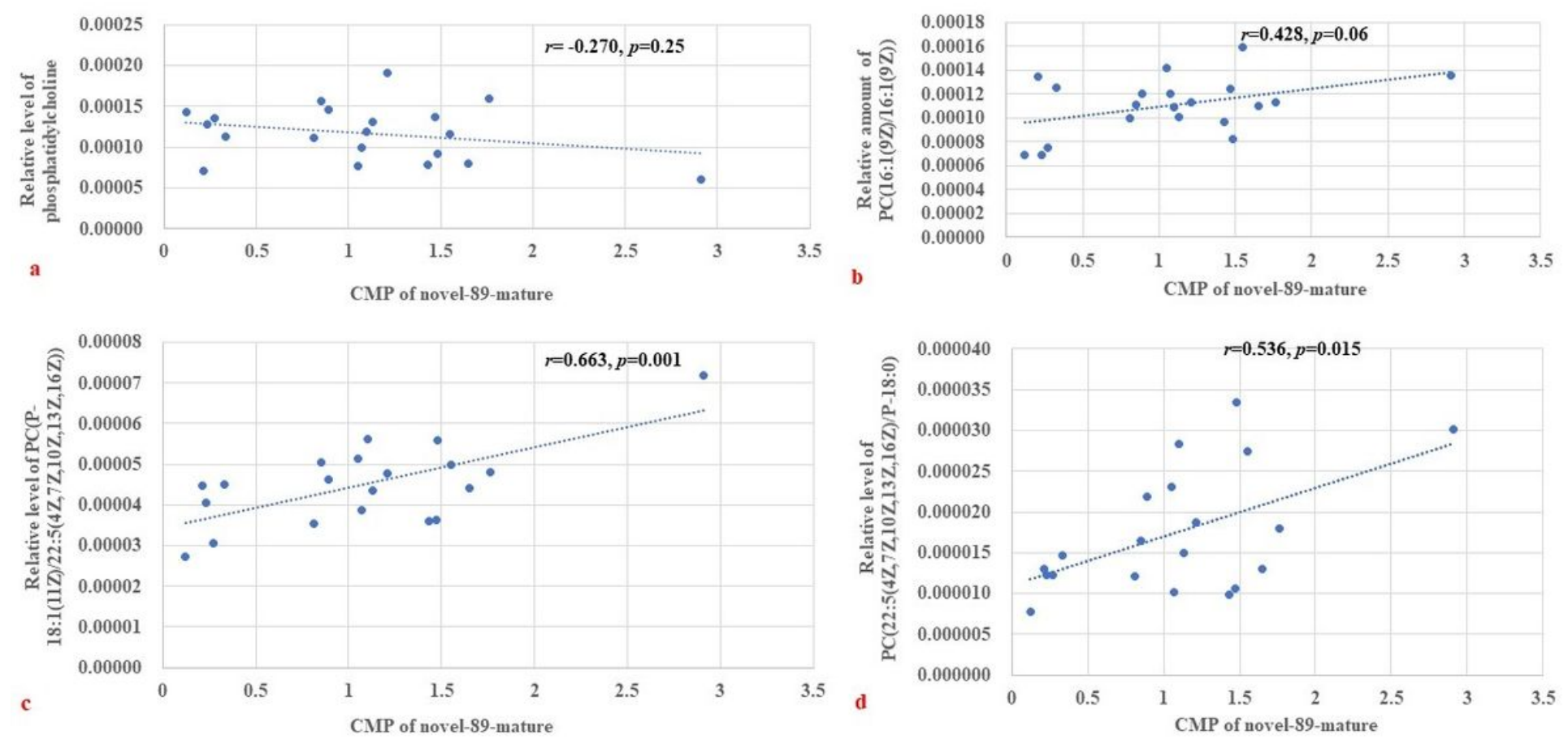

\section{Figure 4}

The analysis of linear correlation between novel-89-mature and metabolites related to phospholipase C. Phospholipase C, gamma 1 (Plcg1) was identified as a core gene, targeted by novel-89-mature, and PC (16:1(9Z)/16:1(9Z)), PC (P18:1(11Z)/22:5(4Z,7Z,10Z,13Z,16Z)), PC (22:5(4Z,7Z,10Z,13Z,16Z)/P-18:0) were the metabolic substrates of phospholipase $C$, and phosphorylcholine was the product of the enzymatic reaction.

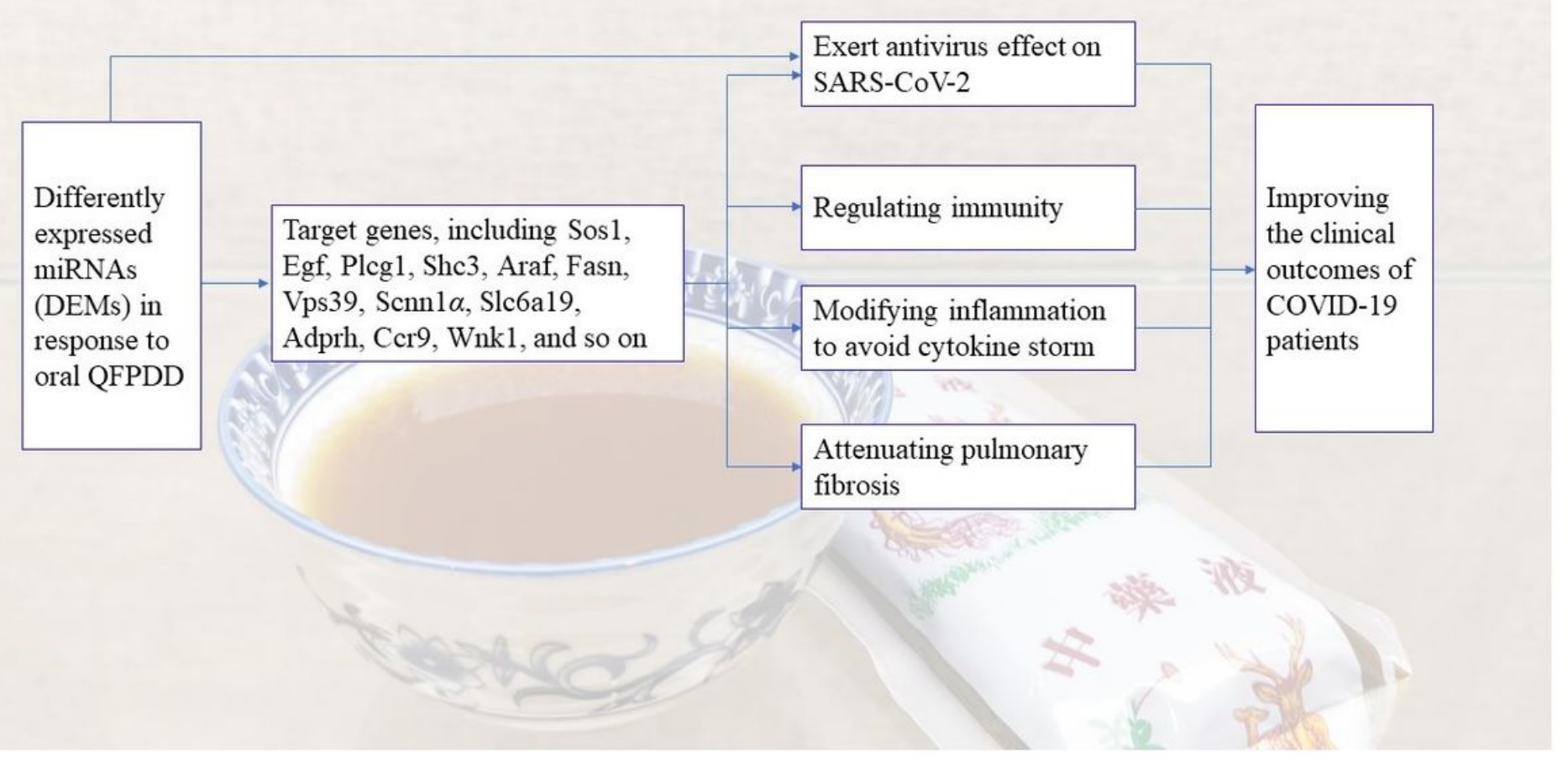




\section{Figure 5}

The multi-action modes of QFPDD through the modification of miRNAs.

\section{Supplementary Files}

This is a list of supplementary files associated with this preprint. Click to download.

- Additionalfile1rawdatasummary.xlsx

- Additionalfile2cleandatasummary.xlsx

- Additionalfile3AnnotationsofcleansRNAs.xIsx

- Additionalfile4knownmiRNAinformation.xlsx

- Additionalfile5novelmiRNAinformation.xlsx

- Additionalfile6CMPofmiRNAdetail.xlsx

- Additionalfile7foldchangemiRNAdetail.xlsx

- Additionalfile8diffexprmiRNAsignificant.xlsx

- Additionalfile9TargetsofdiffexprmiRNA.xlsx

- AF10Potentialrolesinducedbytop100predictedtargets.docx

- AF11GeneFunctionclassificationbyGOenrichment.xlsx

- Additionalfile12totalGOenrichment.xlsx

- AF13GeneFunctionclassificationbyKEGGenrichment.xIsx

- Additionalfile14KEGGenrichment.xIsx

- Additionalfile15aTopKEEGenrichmentnetworkExcel.xIsx

- Additionalfile15bTopKEEGenrichmentnetworkFigure.pdf

- Additionalfile16aPoSorigionaldata.xlsx

- Additionalfile16bNEGorigionaldata.xlsx

- Additionalfile17aPoSnormalizeddata.xIsx

- Additionalfile17bNEGnormalizeddata.xIsx

- Additionalfile18aPOSOPLSDAAnalysisResults.xlsx

- Additionalfile18bNEGOPLSDAAnalysisResults.xlsx 